\title{
Review
}

Asmaa Mohamed El Shafey*

\section{Green synthesis of metal and metal oxide nanoparticles from plant leaf extracts and their applications: A review}

https://doi.org/10.1515/gps-2020-0031

received October 03, 2019; accepted March 28, 2020

Abstract: Metal nanoparticles (MNPs) and metal oxide nanoparticles (MONPs) are used in numerous fields. The new nano-based entities are being strongly generated and incorporated into everyday personal care products, cosmetics, medicines, drug delivery, and clothing to impact industrial and manufacturing sectors, which means that nanomaterials commercialization and nanoassisted device will continuously grow. They can be prepared by many methods such as green synthesis and the conventional chemical synthesis methods. Green synthesis includes infinite accession to produce MNPs and MONPs with demanding properties. The structurefunction relationships between nanomaterials and key information for life cycle evaluation lead to the production of high execution nanoscale materials that are gentle and environmentally friendly. Majority of plants have features as sustainable and renewable suppliers compared with microbes and enzymes, as they have the ability to pick up almost $75 \%$ of the light energy and transform it into chemical energy, contain chemicals like antioxidants and sugars, and play fundamental roles in the manufacture of nanoparticles. Plants considered the main factory for the green synthesis of MNPs and MONPs, and until now, different plant species have been used to study this, but the determined conditions should be taken into consideration to execute this preparation. In this study, we focus on the biosynthesis procedures to synthesize MNPs and MONPs, including comparison between green synthesis and the classical chemistry methods as well as the several new orientation of green synthesis of nanoparticles from different plant parts, especially plant leaf extracts. Plants with reducing

\footnotetext{
* Corresponding author: Asmaa Mohamed El Shafey, Physical Chemistry, Chemistry Department, Faculty of Science and Arts, King Khalid University, Sarat Ebida, Saudi Arabia, e-mail: sommy_28@yahoo.com
}

compounds is the preferred choice for the synthesis of noble metals-metal ions can be reduced to the corresponding metals in the absence of any other chemicals under microwave irradiation conditions using benign solvent, water. Noble metals such as gold $(\mathrm{Au})$, silver (Ag), platinum (Pt), and palladium (Pd) and other metals such as copper $(\mathrm{Cu})$ and nickel $(\mathrm{Ni})$, which are characterized by their optical, electronic, mechanical, magnetic, and chemical properties, leading to different technological applications. Plants with numerous reducing agents are suitable candidates for the manufacture of noble MNPs. The main purpose of this research is to give a background on green nanotechnology prospective evolution, pertinent concerns appeared related to the green synthesis of metal and metal oxide from plant extracts, nanoparticle formation mechanism, and the importance of flavonoids, vitamin $\mathrm{B}_{2}$, ascorbic acid (vitamin C), and phenolic compounds in the MNP and MONP production. The traditional sorghum beers are produced in many countries in Africa, but diversity in the production process may depend on the geographic localization. These beers are very rich in calories; B-group vitamins including thiamine, folic acid, riboflavin, and nicotinic acid; and essential amino acids such as lysine. However, the Western beers are more attractive than the traditional sorghum beers. The traditional sorghum beers have poor hygienic quality, organoleptic variations, and shorter shelf life compared with the Western beers. Many research studies on traditional sorghum beers have been carried out and documented in several African countries, especially the microbiological and biochemical properties, the technologies used in the manufacture processes, and synthetic characteristics of African traditional sorghum beers (ikigage, merissa, doro, dolo, pito, amgba, and tchoukoutou). The excellent resources for the production of greener biomaterials are plants and considerable advances have been achieved in many fields such as biotechnology and gene transfer. The manufactured biological nanomaterials have a great application in the pharmaceutical industry such as novel pharmaceuticals preparation, drug delivery 
personification procedures, and production of functional nanodevices.

Keywords: nanotechnology, MNPs, MONPs, plant leaf extracts, applications

\section{Introduction - prospective evolution of green nanotechnology: greener approach to nanomaterials and their numerous and sustainable implementation}

Global research studies give a great interest to green nanotechnology, as green nanotechnology is a resultant field and nascent branch of nanotechnology.

Green nanotechnology is the perfect solution to decrease the negative effects of the production and application of nanomaterials, lowering the nanotechnology riskiness [1]. Figure 1 shows the key merits of green synthesis. The generation of engineered nanomaterials represents an essential breakthrough in nanotechnology and materials science. The real world should be created by moving these products beyond the laboratory. More than thousands of such products are available in the market, of which a large majority are integrated in everyday personal care products, cosmetics, and clothing. Development of the modern products that consumers need are expected to affect positively almost every industrial and production sectors, involving medicine and drug delivery. The continuous growth of the nanomaterials marketing and nano-assisted device is very obvious [2]. The commercialization of successful disruptive technologies is fundamental for numerous implementations to humans and global development, but critical interest is necessary for potential, health assessment and environmental effects of these materials [2-5]. It is a clear reality that the health hazards due to nanoparticles exposure are slowly comprehended and need to be addressed rapidly [6] and their manufacture and utilization are practically uncontrolled [7], particularly in the universe development. This is predominately discouraging when the new nano-based entities are being generated and incorporated into consumer products at an alarmingly quick rate, thus oversight mechanisms is an urgent need since the final existence of the majority of the nanotechnology innovations resulted from the research groups which considered simple startup work must based on instructions and recommendation from regulatory bodies and should not be oppositely affected by the boosted cost loads connected with such increased oversight [8]. Health and safety regulations will have to carefully negotiate regulatory testing cost load, which will in turn have an essential role in giving priority to hazards associated with nanomaterials [9]. The essential aspect of the green chemistry emerging sector is the utilization of a group of basics lowers or removes the hazardous substances utilization or generation concerning design or production and chemical products' application while designing new chemical processes visualizes small risk as the execution criteria.

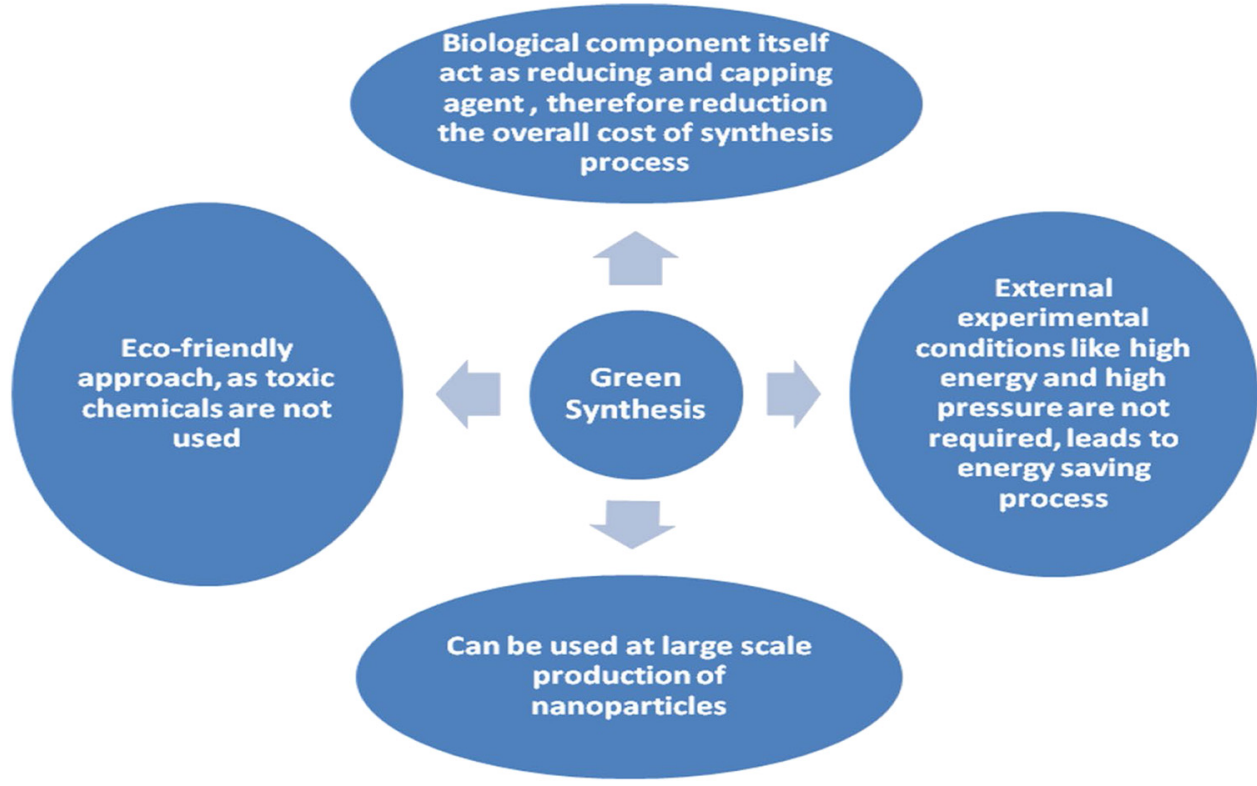

Figure 1: Key merits of green synthesis [26]. 
Green chemistry basics implementation in the new materials expansion and enforcements is all the more considerable in opinion of the principle that the technology is an early expansion phase and is foreseeable to be widely utilized and doled out around the world. The strong relation between chemical structure and function groups that connects specifically to nanomaterials and boosting understanding "key" information for life cycle evaluation of such methods could lead to new "design principles" for the production of high rendering nanoscale materials that are benign and environmentally friendly [10].

The molecules, cells, and organs of the aforementioned plants have been bioengineered to provide new nanomaterials with demanding sustainable advantages. Green nanotechnology gives us the chance to prevent the negative effects. Green nanotechnology has an enterprising effect on the nanomaterials or the products design by removing or lowering pollution, which means that it remediates the existing environmental problems, as indicated in Figure 2. The environmental friendly methods such as catalytic potential [11], electrical conductivity [12], optical sensitivity [13], magnetic behavior [14], or biological reactivity [15] are used to characterize the chemical, physical, and biological properties of nanomaterials in addition to many factors such as size, shape, surface charge, chemical structure, surface area, and coagulation properties of nanoscale distinct materials [16]. The organic solvents and chemical reagents are not used in the preparation of metal nanoparticles (MNPs ). MNPs have unique properties with their nanostructures [17]. The atoms ordered to the nano-scale differ from the bulk metallic materials [18], and the unique properties of MNPs and metal oxide nanoparticles (MONPs) are engendered from them. MNPs and MONPs have many applications such as catalysts [19]; drug delivery systems [20]; boosting contrast agents [21]; active food packaging materials [22]; components pointing to nano-biosensor construction [23]; gene transfer

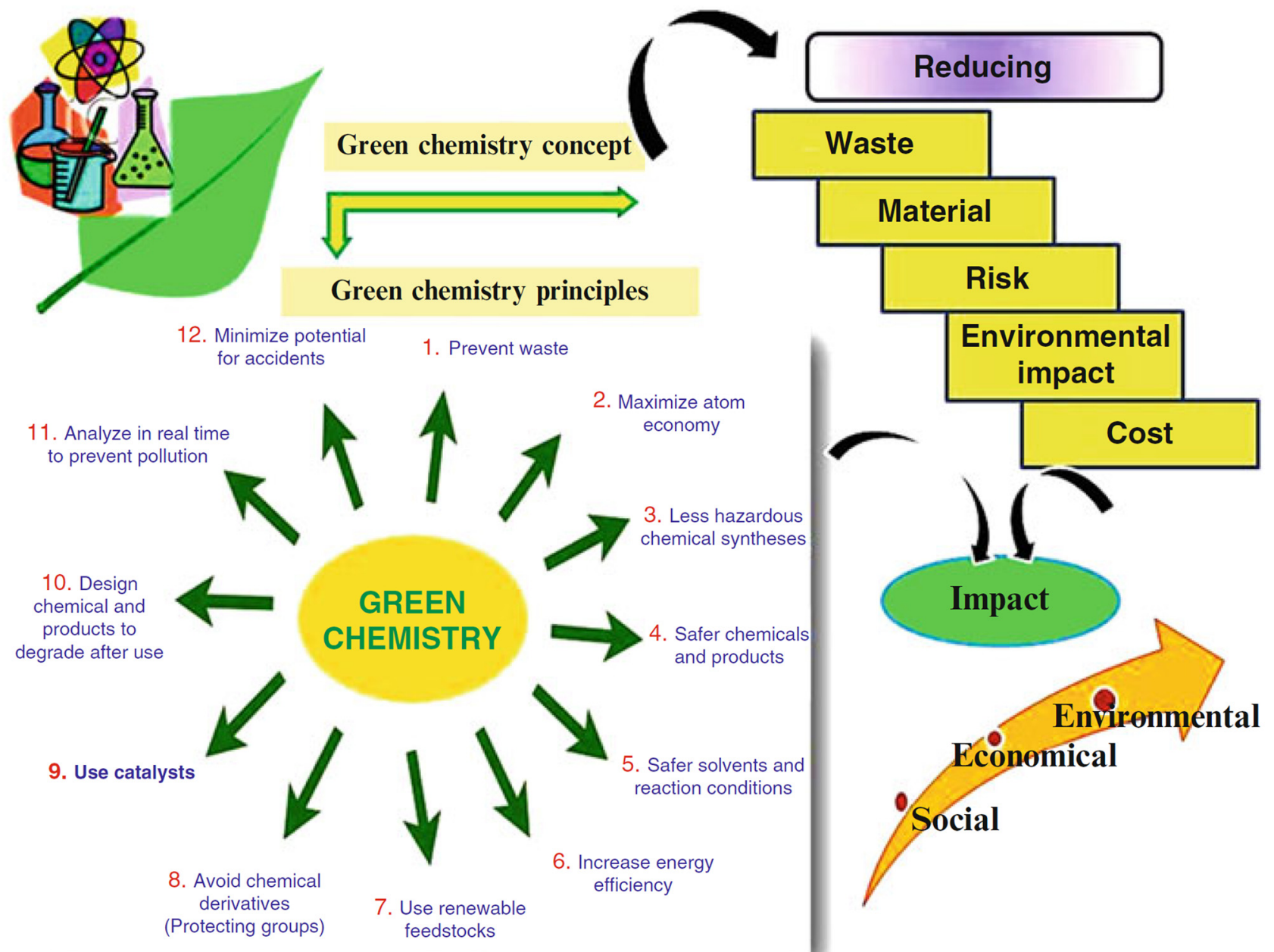

Figure 2: Schematic exemplification of green chemistry combination in metal nanomaterials cloning [27]. 
system [20]; antibiotics, antiseptics, and disinfectants to control pathogens and pests [24]; and nanoelectronic components [25].

\section{General consideration taken into account for MNPs and MONPs synthesis}

To synthesize MNPs and MONPs, researchers used a strong base (reducing agent), e.g., sodium borohydride or sodium hydroxide, in metal ion reduction from salt solutions, followed by the addition of a capping agent or a stabilizer (stabilizing agent) [28], as indicated in Figures 3 and 4.

To dissolve the stabilizers, they used solvents and the reagents that act as reducing agents, which are toxic substances and have counteractive and harmful effects if the rest of these materials are left in the rear part of the nanosystem, as the bottom-up path to synthesize the nanoparticles often needs the offensive chemical reduction agents such as sodium borohydride and hydrazine and a capping agent and may also involve a volatile organic solvent such as toluene or chloroform. Although these procedures may effectively produce pure products [32], the manufacturing cost is very high, both materially and environmentally. This may provide new stand by accession achieving this synthesis and steer them to consider safety applications of MNPs and MONPs [33]. The green synthesis of MNPs and MONPs is considered one of the alternatives that depends on the green chemistry principles by using the biological systems [34-37]. The green synthesis of MNPs and MONPs is accomplished by using prokaryotic [38] or eukaryotic [13] organisms (involving microorganisms, plants, and animals) or their parts, and can take place intracellularly [39] or extracellularly [40]. The primary and secondary metabolites of plants are used to produce MNPs and MONPs by executing a target metal ion reduction, as shown in Figure 5.

Formation of coating layer (stabilizing layer) on the surface of the MNPs and MONPs by reducing compounds or other besetment molecules lowering them to coagulate/ aggregate otherwise ordered in an upset way within their preparation [42]. MNPs and MONPs preparation and their properties can be polished by setting different conditions such as temperature, $\mathrm{pH}$, and reagent concentration [12]. The scientists have utilized the organ/tissue extracts or the whole organisms [43,44] of plants to execute the green synthesis of MNPs and MONPs. Various plant parts such as leaves, seeds, barks, roots, and fruits, is the factory for the nano-object production with different properties [45,46], but the researchers should consider the specific phytochemical profile of each plant part with different structures and concentrations according to the needs of each organ and the type of biotic or abiotic stress to which a plant may be exposed, as indicated in Figure 6.

\section{Plants are the main factory for the green synthesis of MNPs and MONPs}

The green synthesis of MNPs and MONPs may be done by using the living organisms, which symbolize the kingdom of the biology system. The living organisms are not only necessary for food and nutritional purposes but also used in green synthesis. Due to the biomass abundance of many plants, the scientists give priority to the plants to execute the green synthesis of MNPs and MONPs because of their molecular ammunition and biomass profusion. The resulted response to the stress factors (pathogens, herbivores, and climate changes) and survival agents (seasonal changes and reproductive manner) concerning plants are affected by the primary and secondary metabolites of the plants, and these strategies will make the plants the main bioreactors and molecule suppliers for green synthesis [48]. Due to the presence of metallic counterparts and the stabilization of the surface of the MNPs and MONPs [41], the primary compounds of plants such as amino acids [49], citric acid [14], flavonoids [50], phenolic compounds [51], terpenoids [52], heterocyclic compounds [53], enzymes [54], peptides [55], polysaccharides [56], saponins [57], and tannis [58] are responsible for the metal ion reduction. The whole organs/ tissues [43,44] or the extracts of the organs/tissues and different parts (e.g., seeds, leaves, barks, roots, and fruits) of the plants are utilized for the green synthesis of MNPs and MONPs and may produce nano-objects with several properties [59,60], so we deal with each part of the plants discretely for their different concentrations and their unique phytochemical characterization, and this depends on the biotic or abiotic stress type to which a plant perhaps subjected and the needs of each organ.

\section{Modern orientations}

The research studies on the green synthesis of MNPs and MONPs using plants can easily understanding the molecular mechanism, coordinating bioreduction, nucleation, 

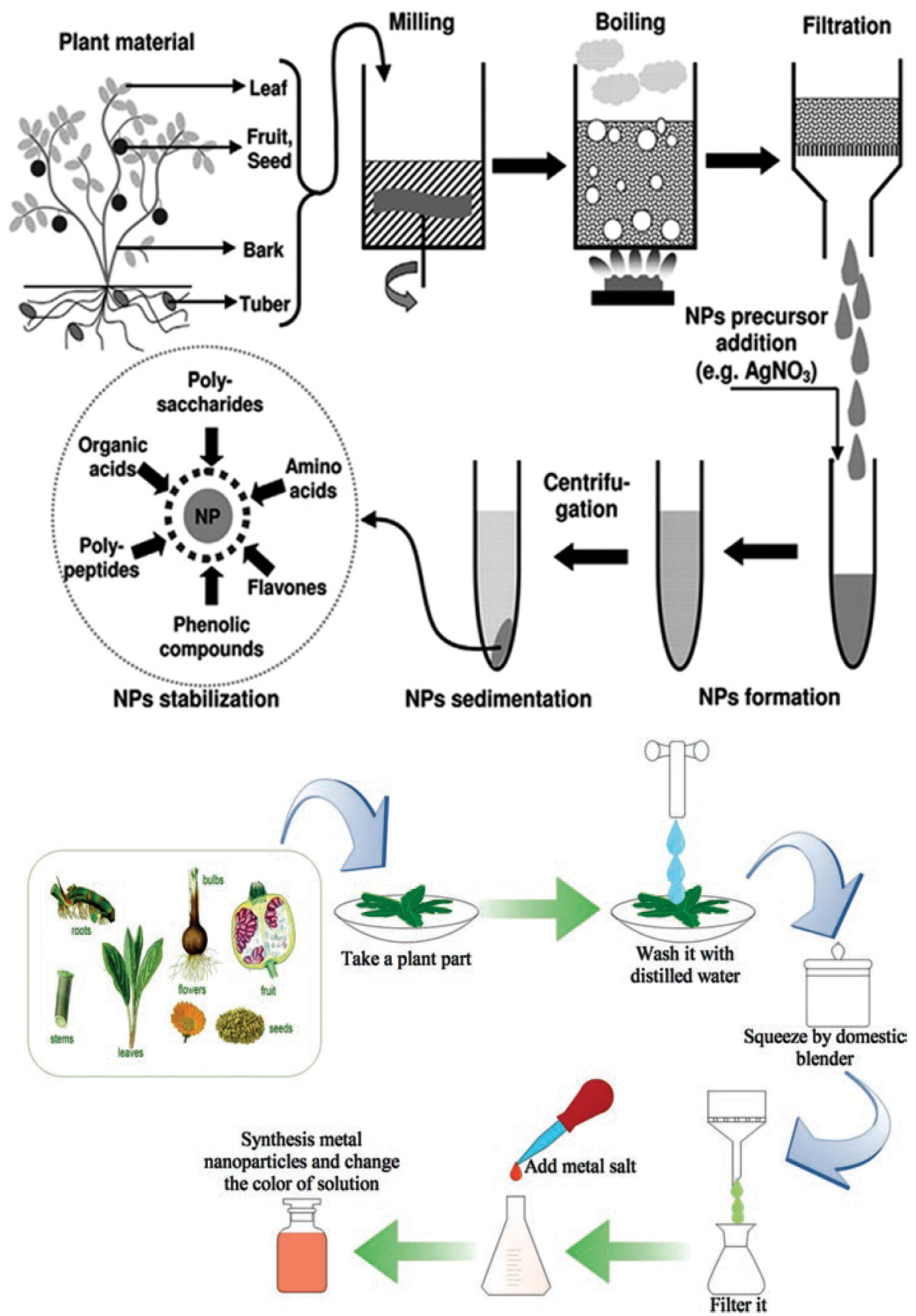

Figure 3: Two schematic features of MNP synthesis using plant extracts $[29,30]$.

growth, and stability. The first stage was utilization of the plant extracts selected from the endemic or global biological variation. The extract from different plant parts and species in the presence of metal salts results in the production nanoparticles of different sizes, shapes, compositions, and activities, as indicated in Figure 7 . 


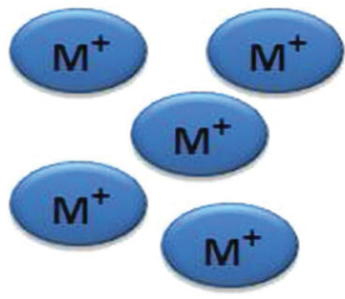

Metalions
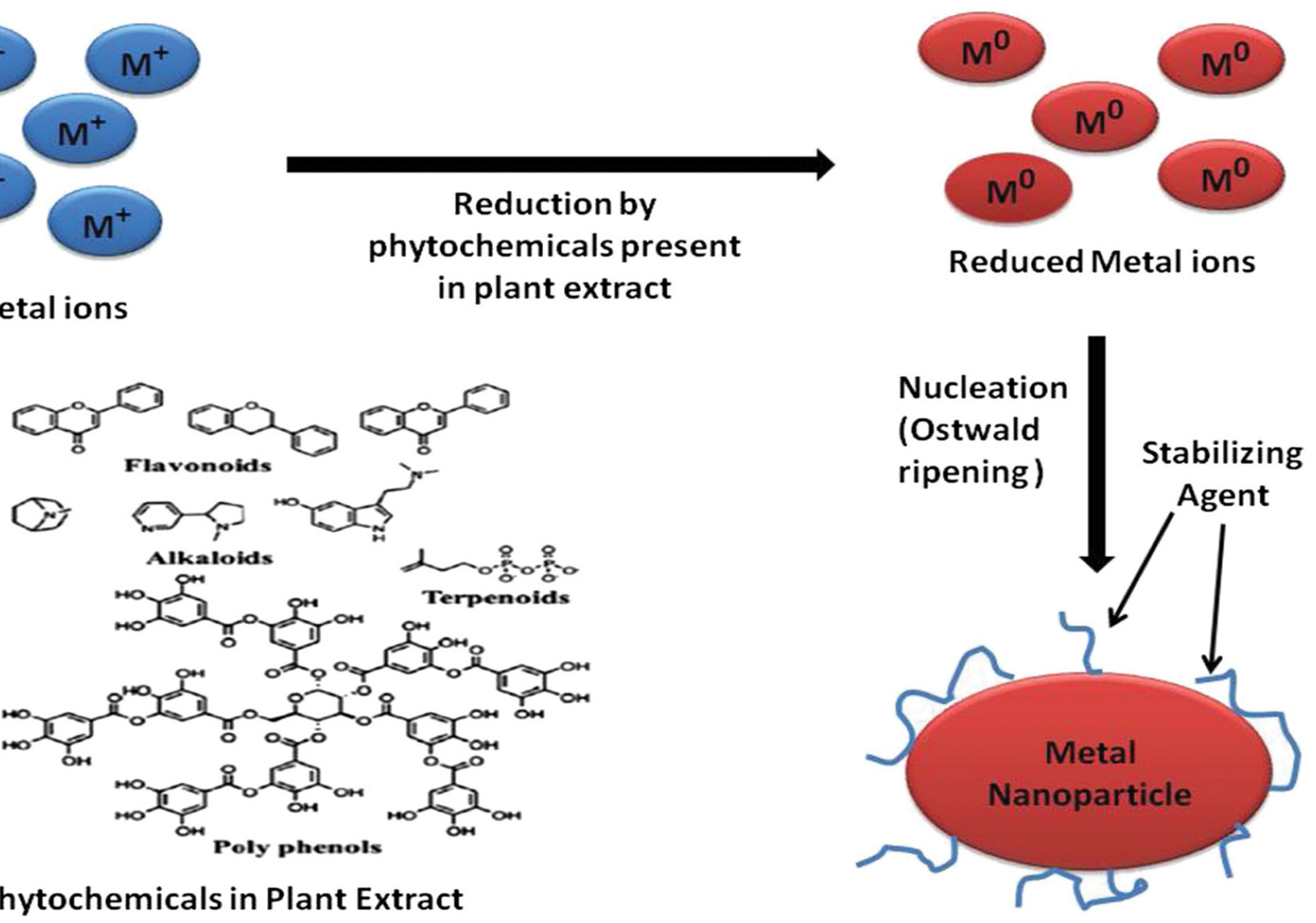

Figure 4: Nanoparticle consistency mechanism by plant leaf extract [31].

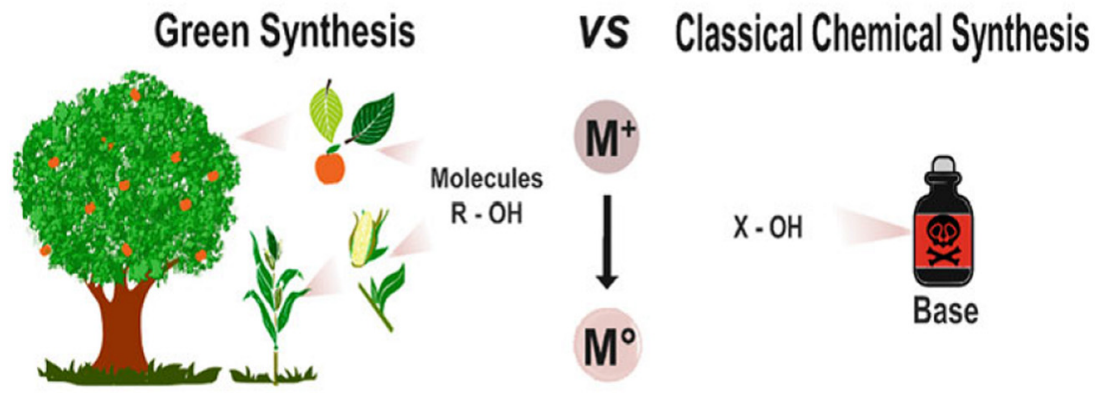

Figure 5: Schematic explanation of the two main approaches used for the synthesis of MNPs and MONPs: green and chemical (classical) synthesis. Dicotyledons and monocotyledons are used as the reducing and stabilizing agents in the metal salt reduction for the green synthesis of MNPs and MONPs [41].

Reduction of noble metals [12,42,43,61,62] including gold $(\mathrm{Au})$, silver $(\mathrm{Ag})$, and platinum $(\mathrm{Pt})$ and other metals such as copper $(\mathrm{Cu})$ was studied in many research studies on the green synthesis of MNPs and MONPs.

\subsection{Noble metal synthesis}

Noble metals are characterized by their optical, electronic, mechanical, magnetic, and chemical properties, which attract interest and lead to various applications in different technological applications [63-68]. MNPs are synthesized by using extremely reactive reducing agents, e.g., sodium borohydride $\left(\mathrm{NaBH}_{4}\right)$ and hydrazine, which are not ecofriendly. The use of toxic chemicals in these methods limits their use due to environmental precautions. The plants ability to synthesize MNPs has conquered a new axis and spectacular approach toward the development of natural nano-factories. Majority of plants have features as sustainable and renewable resources compared with microbes and enzymes as they have the ability to pick up nearly $75 \%$ of 


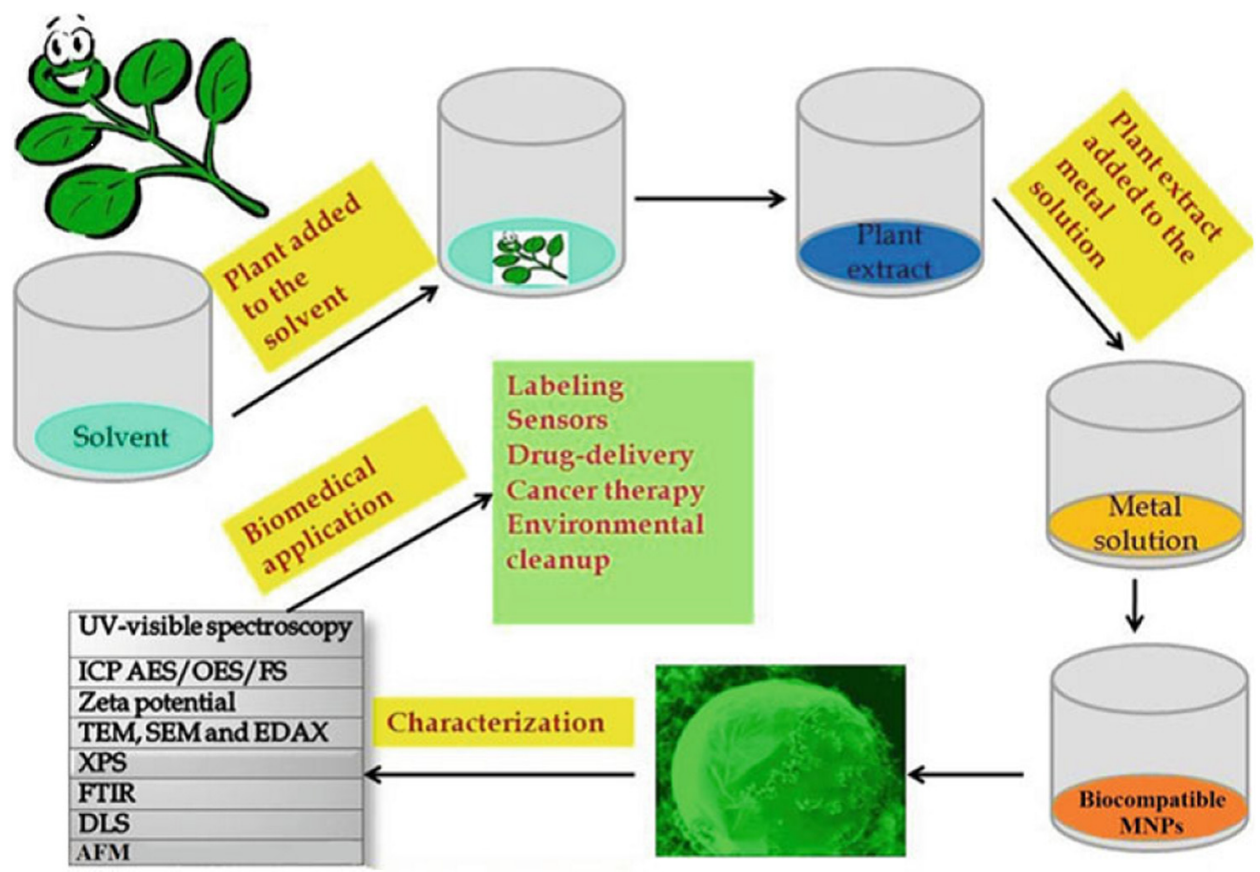

Figure 6: A schematic illustration of plants as a source for the green synthesis of nanoparticles and the properties and biomedical implementation of nanoparticles [47].

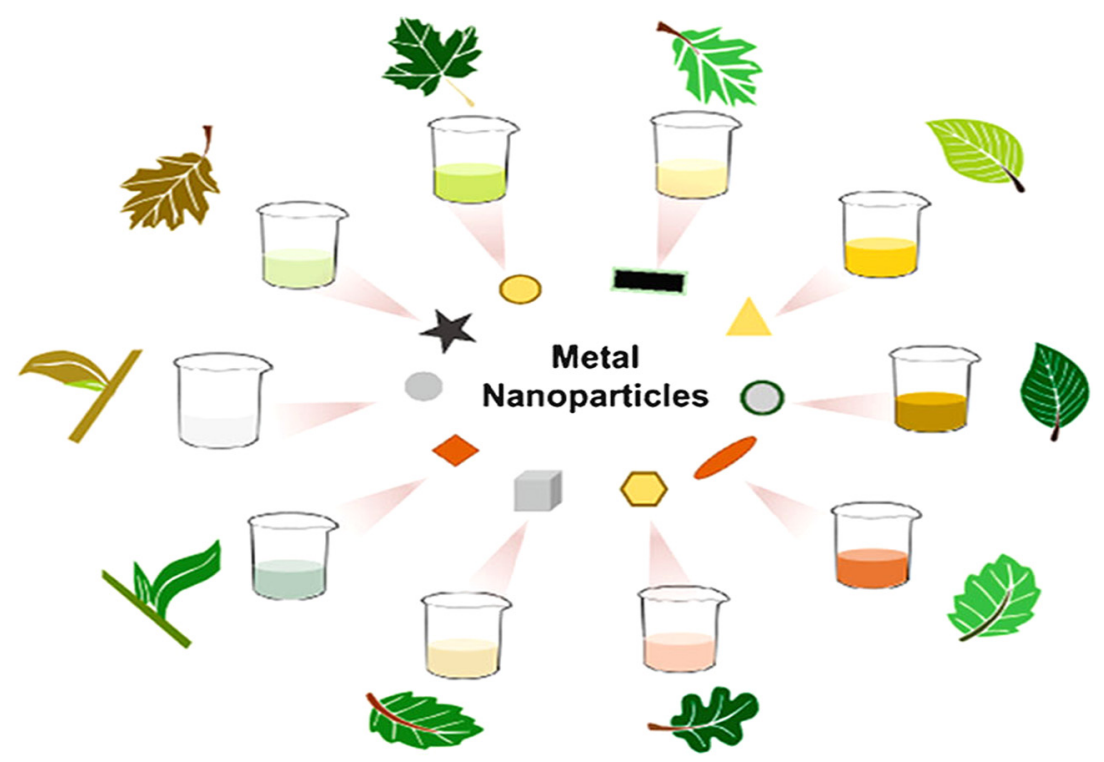

Figure 7: Green synthesis of MNPs using the extracts obtained from the leaves of different plant species leading to the production of structures with different compositions, shapes, and sizes [41].

the light energy from sun and convert it into chemical energy, which needs expensive production methods [69-72]. Furthermore, plants contain chemicals like antioxidants and sugars and play essential roles in the manufacture of nanoparticles [73-77].

Consequently, a pressing need to promote more costeffective and environmentally friendly alternatives to these existing procedures, the environmentally compatible solvent system choice, using an eco-friendly reducing agent for stabilizing the nanoparticles are three essential criteria for a "green" nanoparticle synthesis [70].

\subsubsection{Beet for green synthesis of MNPs}

The preferred choice is plants with reducing compounds for synthesis of noble metals as the corresponding 
metals, which are produced by the reduction of metal ions in the absence of any other chemical materials [70-72,78,79]. The reducing agent is an essential factor in the synthesis of noble MNPs by the corresponding metal ion salt solutions; hence, plants with various reducing agents are favorable candidates for the manufacture of noble MNPs. Beet is a bountiful agriculture product and it belongs to the Chenopodiaceae family. Its purple root is fundamental in the production of table sugar and mangelwurzel. It has a great reductive capability because of sugar-rich content, which can be used in the synthesis of nanomaterials, but it has not been investigated in detail $[80,81]$. Beet juice was utilized for the synthesis of nanometals such as Ag, Au, Pt, and Pd under microwave (MW) irradiation condition using benign solvent, water. For example, the prepared Ag nano-particles exhibit perfect catalytic efficiency in converting 4-nitrophenol to 4aminophenol with elevated reuse, which is higher than $\mathrm{NaBH}_{4}$ [82].

The green synthesis of MNPs and MONPs using plants [12,83-85] helps researchers understand and determine the characteristics of MNPs and MONPs. The shapes of the MNPs and MONPs are usually spheres $[3,83-85]$ and triangles $[84,86]$. Their size is in the range of 15-50 nm of hydrodynamic diameter [87].

MNPs and MONPs produced by green synthesis using plants have various activities such as antibacterial $[88,89]$, antifungal [12], anticancer [90], and larvicidal [91].

The MNPs and MONPs were also produced by green synthesis using various plant organs such as seeds, bark, flowers, tubers, and root extracts [42] but leaf extract is the most important for the production of MNPs and MONPs as it is the major resource for metabolites because they are rejuvenated and non-devastating compared with other plant tissues. MNPs and MONPs synthesis and characterization were affected by different factors such as the season or the plant organs collection place in addition to abiotic existence (cold, water, metal existence, or pesticides) or biotic (pest or pathogen existence) compression agents. Plant designs are essential for scaling-up of MNPs and MONPs production and reproducibility. By using various plant extracts, we can synthesize MNPs and MONPs with nanoscale features, and researchers can moderate more condition for the synthesis. The qualification and velocity of the green synthesis of MNPs and MONPs sympathize the model lineaments of the traditional chemical synthesis. Controlling MNPs and MONPs synthesis factor variation is very important to produce MNPs and MONPs with demanding properties and provide background on consistent mechanism $[88,89,92]$. The green synthesis of MNPs and MONPs happens in the plant in vivo $[93,94]$. The binding and complexation process with phytochelatins and secondary metabolites [95-98] causes a stress, which affects the plants, and it is a slower and more expensive process than the green synthesis processes of MNPs and MONPs from the plant extract.

\section{Synthesis of MNPs and MONPs by utilizing plant leaf extract}

The biovariations of plants offers a plentiful biochemical properties and introduces particular source to synthesize nanoparticles [99]. The extract from the plant leaf can be obtained very simply to use and has numerous metabolites that act as reducing agents to synthesize nanoparticles [100]. A solution containing metals such as nickel, cobalt, zinc, and copper is mixed with the extract of the plant leaf at room temperature [101]. Different factors such as $\mathrm{pH}$, temperature, contact time, metal salt concentration and phytochemical profile of the plant leaf particles affect the nanoparticles goodness, nanoparticle stabilization, quantity produced, and yield rate. The metal ion reduction in plants is faster than that in fungi and bacteria, as they need a long time for incubation because of the presence of water-soluble phytochemicals [102].

The numerous phytochemicals present in the plant leaf extracts can be extracted facilely [103,104], so the plant leaf extracts are considered as a wonderful tool for MNPs and MONPs synthesis.

The advantage of plant leaf extracts to act as stabilizing agents and reducing agents facilitates the nanoparticle synthesis [99]. Biomedical reducing agents are present at different concentrations in different types of leaf extracts, so the leaf extract composition has a great effect on the nanoparticle synthesis $[105,106]$. Terpenoids, flavones, ketones, amides, aldehydes, and carboxylic acids are the essential phytochemicals involved in the nanoparticle synthesis [100].

\section{Nanoparticles synthesis from plant leaf extracts mechanism}

Proteins and carbohydrates are important constituents of the plant extracts, which act as reducing agents and are responsible for the formation of MNPs and metal ion reduction [107].

Functional amino groups and proteins in the plant extracts play an essential role in the metal ion reduction 
(a)

1
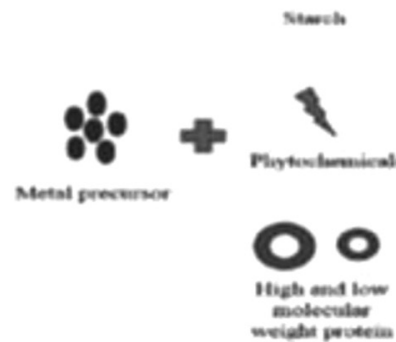

weight pouteia

(b)

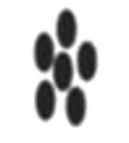

Mctal icos

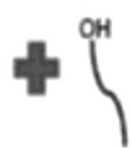

Plant roduciag agents

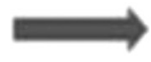

REDUCTION
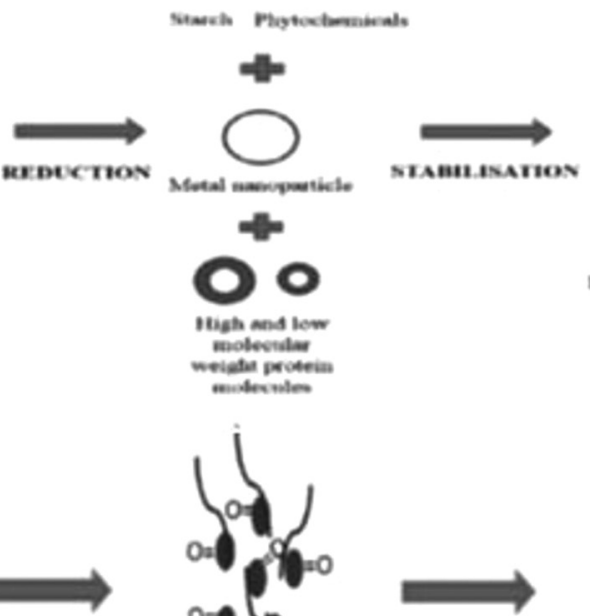

NUCLEATION<smiles></smiles>

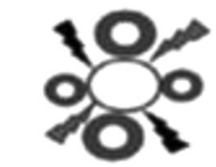

Mecal anangarticle atabliened with

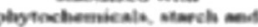
proterims

(c)

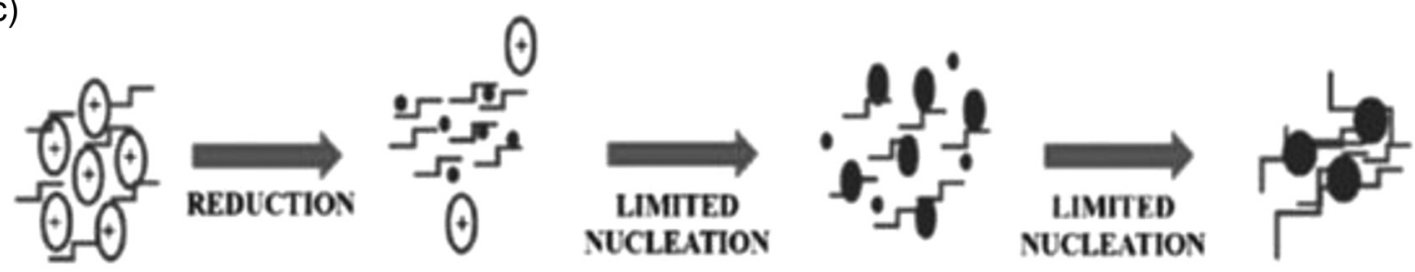

(d)
$\oplus$ Metal ions
- Proteins in plant extracts
- Metal Nanoparticle
Metal Nanoparticle

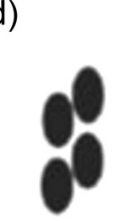

Metal precursor

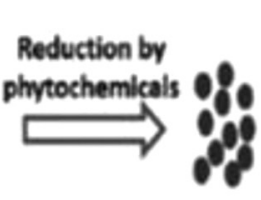

Metal ions

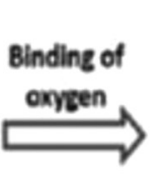

$$
\begin{gathered}
\text { Oxygen binding } \\
\text { either from } \\
\text { atmosphere or } \\
\text { from degrading } \\
\text { phytochemicals }
\end{gathered}
$$

Figure 8: Metal and metal oxide nanoparticles formation mechanism by phytochemicals: Metal and metal oxide nanoparticle formation by phytochemicals: (a) the use of high- and low-weight phytochemicals, proteins, and starch mixtures present in the plant extracts with metal precursor. (b) proteins of plant extracts act as a reducing and stabilizing agents and the metal atom will be encapsulated as organic covering in three steps. (c) metal ion reduction and reduced metal ion nucleation will be in the activated phase to have the final shape of the nanoparticles formed during the termination step. (d) the MONPs production mechanism which may also be executed by different methods $[26,100,105,106,109-116]$. 
[108]. Huang et al. [109] discussed that the functional groups of alkaloids, flavones, and anthracenes, such as $-\mathrm{C}-\mathrm{O}-\mathrm{C}-,-\mathrm{C}-\mathrm{O}-,-\mathrm{C}=\mathrm{C}-$, and $-\mathrm{C}=\mathrm{O}-$, assist the MNP synthesis.

Kesharwani et al. [110] proposed that the metal ion reduction may be carried out with the help of quinones and plastohydroquinone molecules present in the plant leaf extract, which indicate that the extracellular MNP synthesis can be done by biomolecules and heterocyclic compounds in plants. Despite the complete vision of MONP synthesis by using plants is not well understood until now, the phytochemicals of the plants led to the production of MONP, like MNP.

First, the phytochemicals of the plant extract are responsible for the metal reduction. Oxygen produced from either atmosphere or degrading phytochemicals links the reduced metal ions. Electrostatic attraction will link metal oxide ions to each other and lead to the formation of nanoparticles. They are stabilized by phytochemicals that prevent agglomeration between them.

The superoxide-driven Fenton reaction is the main provenance for reactive oxygen species (ROS) [111] and is repressed by the phenolic compounds with carboxyl groups and hydroxyl groups of plants. Mukherjee et al. [112] suggested the use of high- and low-weight phytochemicals, proteins, and starch mixtures present in the plant extracts, as indicated in Figure 8a. Newman et al. [113] also explained the possibility of the production of MNPs and MONPs by proteins of plant extracts, which act as reducing and stabilizing agents, as mentioned in Figure 8b.

Markarov et al. [114] proposed that metal atoms will be encapsulated as organic covering in three steps for their magnitude stabilization after reduction by plant extracts, as shown in Figure 8b. Metal ion reduction and nucleation of reduced metal atom will be in the activation phase, the nanoparticle stability increased through the growth phase, and the shape of the nanoparticles formed during the termination phase, as indicated in Figure 8c [115]. They could summarize the process by the following steps:

(1) The metals such as copper, silver, gold, zinc, titanium, iron, and nickel result in the formation of their metal oxides by phytochemicals.

(2) Using phytochemicals, metal ions will go through growth and stabilization phases.

(3) Oxygen is produced either by degradation of phytochemicals or by atmosphere, and before growth and stabilization phases, it will be linked to metal ion as mentioned in Figure $8 \mathrm{~d}$ which explains the MONPs production mechanism may also be executed by different methods described in the literature $[26,100,105,106,116]$.

\section{MNPs green synthesis: stabilization and functionalization by using biodegradable polymers and enzymes}

The high chemical activity with an improved surface of the engineered nanoparticles is mainly because of the unfavorable intense and predominantly irreversible operations like aggregation [117]. Reduction of the specific surface area and the interfacial free energy can be achieved by aggregation, thereby minimizing the particle reactivity (Scheme 1) [118], so it is fundamental to boost the nanoparticle stability improvement during storage, transportation, and its overall life cycle. The majority of the stabilization methods involve Dispersant molecules such as surfactants or polyelectrolytes, which not only modify the chemistry and nanoparticle surface physics but also fabricate an enormous waste stream because they take up a worthy (more than 50\%) of the nanoparticle mass fraction system [119]. Hence, there is a necessity to find environmentally benign stabilization and functionalization passages as well as bioconvenient to obviate pollution and the following counteractive effects on the environment, i.e., non-immunogenic, nontoxic, and hydrophilic stabilizing agents. Different stabilizing agents are used to prevent the aggregation of the nanoparticles and to functionalize the particles for the desired implementation at the same time [120-122]. However, the usual acute reaction conditions and the toxic chemicals may not be appropriate for the biological and biochemical implementation [123]. Presently, there are numerous "green stabilizing agents" such as polyphenols, enzymes, citric acid, vitamins (B, C, D, and K), biodegradable polymers, and silica, which has the ability to stabilize and functionalize MNPs without the unfavorable effects on the environment and biosynthesis.

\subsection{MNPs recoverability and reusability}

It is very substantial to functionalize and stabilize MNPs for varied implementation; however, simple and relatively low-cost recoverability and therefore nanoparticleś reuse is currently acquiring an increased attention among the scientific society. Nanoparticles have magnetic properties have been inclusively used in the metal ion and dye coat, drug delivery, enzyme 


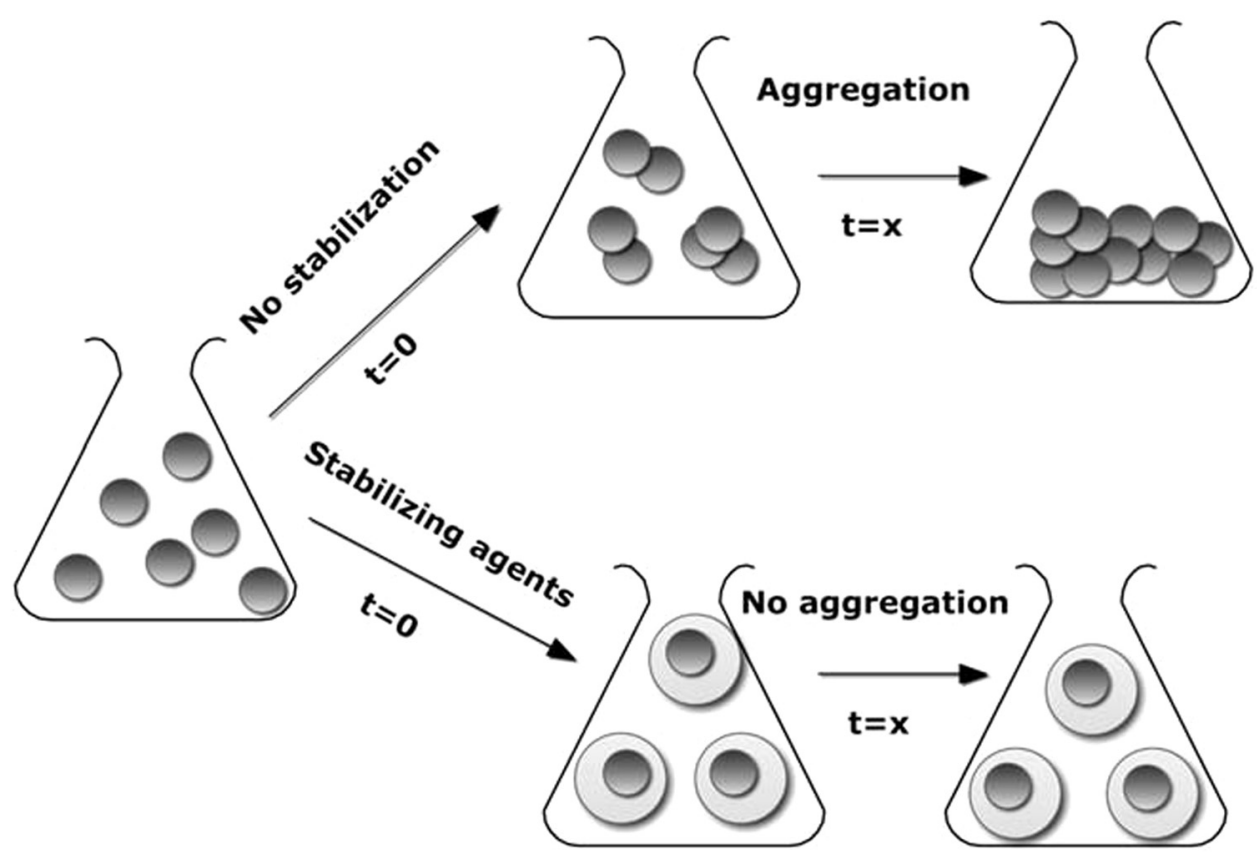

Scheme 1: Schematic of nanoparticle aggregation in the presence and absence of the stabilizing agents [70].

immobilization, and protein and cell separation fields because the magnetic separation of these nanoparticles offers individual high competency and cost leverage and is fast in comparison with other nanoparticles, which are harmoniously emerging as heterogeneous supports (so called magnetic nano-cores) in numerous catalytic transformations, providing easy recoverability with easy magnet advantages, thereby eliminating solvent swelling exigency before or catalyst filtration after the reaction [124-127].

\subsection{Biodegradable polymers}

Biodegradable polymers perhaps produced from numerous renewable sources (corn, wood, cellulose, polylactides, thermoplastic starch, plant oils, gelatin, and chitosan), petroleum sources (aliphatic polyesters or aliphatic-aromatic copolyesters), small molecules in bacteria, or biomass and petroleum mixtures [128]. Rozenberg and Tenne [129] debated the nanoparticles stabilized by surface active polymers, which are adsorbed strongly on the particle surface due to the van der Waals attractive forces between the surface of the particle and the monomer units in polymer chain, preventing the aggregation because of their large surface energy minimization in comparison with the native particles. Block copolymers are even stronger nanoparticle separation and show individual properties such as surface reactivity, flexibility, selectivity, and impedance [130]. MNPs stabilization can be fulfilled by metals in a polymer gel simple enclosure, free radical polymerization with a radical initiator [131], thiol-supported polymer adsorption [132], or in situ MNPs formation during polymerization [132-134].

\section{Greener synthetic strategies}

The preparation of nanomaterials via several chemical methods using benign reagents in the matrix, in which they are to be utilized, need to develop "greener" synthetic strategies, thus reducing or eliminating the utilization of normally used hazardous substances, exposure to them, and generation risk.

\subsection{Polyphenols of plants and agricultural residues}

Nanometal/nanometal oxide/nanostructured polymer synthesis and following stabilization (using dispersants, biodegradable polymers, among others) in a "greener" fashion include the use of natural renewable resources such as plant extracts and polyphenol antioxidants from 
tea and coffee [71], biodegradable polymers such as carboxymethyl cellulose (CMC) [135], reducing sugars [136], and agricultural residual waste (red grape performance from winery waste) [72].

\subsection{Vitamins}

Nanoparticles preparation by using sustainable synthetic activity involves benign alternatives, which reduce or remove the use and production of the risky substances. Vitamins $B_{1}$, Vitamin $B_{2}$ [137], vitamin C [138], tea [71], and wine phenols [72], which all act as both reducing and capping agents. They offer extremely simple one-potgreen synthetic methods to synthesize bulk quantities of nanospheres, nanorods, nanowires, aligned nanobelts, nanoballs, and metals nanoplates in water without the need of large amounts of insoluble templates [10,137].

\section{MNP and MONPs synthesis by using flavonoids as a fundamental agent}

Flavonoids are considered a fundamental agent for the MNP and MONPs synthesis. Flavonoids include anthocyanins, isoflavonoids, flavonols, chalcones, flavones, and flavanones [114], which are considered a group of phenolic compounds. Aglycone is the major structure of flavonoid. The presence of benzene ring is the base on which flavonols, flavanones, or its hydro derivatives are categorized. The position of the benzenoid substituent divides the flavonoid into 2-position flavonoids and 3-position isoflavonoids. The $\mathrm{C}_{2}-\mathrm{C}_{3}$ double bond and the hydroxyl group at the 3-position distinguish flavonols from flavanones [139]. These compounds can reduce metal ions to produce nanoparticles and chelate metal ions. Flavonoids have different functional groups, which have the ability to produce nanoparticles. Reactive hydrogen atoms are released during the tautomeric conversion of flavonoids from the enol form to the keto form, which is responsible for the metal ion reduction to produce nanoparticles [114]. Ahmad et al. discussed the silver nanoparticles production and found that the enol- to keto-form transformation is the main reason for silver nanoparticles production from silver ions by using Ocimumbasillicum extracts and transformation of flavonoids such as luteolin and rosmarinic acid [140].
Zheng et al. [141] indicated that flavonoids content of the plant extract facilitates the platinum ion bioreduction to synthesize the platinum nanoparticles. The internal mechanism; ketone conversion to carboxylic acid in flavonoids; leads to metal ions formation such as $\mathrm{Fe}^{2+}$, $\mathrm{Fe}^{3+}, \mathrm{Cu}^{2+}, \mathrm{Zn}^{2+}, \mathrm{Al}^{3+}, \mathrm{Cr}^{3+}, \mathrm{Pb}^{2+}$, and $\mathrm{Co}^{2+}$ by their carbonyl groups or $\pi$-electrons [114]. In brief, flavonoids are responsible for chelation and reduction to produce nanoparticles through growth, nucleation, and stabilization. Nanoparticles may be produced by combination of phytochemicals or flavonoids. Metal ion may be reduced by phenolic compounds, which are phytochemicals [142-145]. Holtz et al. [146] discussed that MONPs may be synthesized by using terpenoids as a reducing agent. Laghari et al. [147] proposed that MONPs may be produced by using alkaloids from the plant extract. Phytochemicals in the plant extract play an essential role in the MONP formation, so it should be taken into consideration [148-150]; however, the definite role of phytochemicals in the nanoparticle synthesis has not been determined yet. The plant leaf extracts that contain flavonoids are more effective than other phytochemicals, as flavonoids reduce nano-composition toxicity and they act as a stabilizing agent. ROS produced from metal oxides can be reduced by flavonoids due to their antioxidant activity [151,152]. Flavonoids have hepatoprotective [153], anticancer [154,155], and antiviral [156-159] properties. The MONPs formation by using plant extracts containing large amount of flavonoids make them gain more properties, which lead to many important applications.

\section{Vitamin $B_{2}$ as a double agent (reducing agent and capping agent)}

Vitamin $B_{2}$ functions as both a reducing and a capping agent as it manifests to be a quixotic multifunctional agent in the manufacture of nanomaterials and it has high water solubility, biodegradability, and low toxicity compared with other reducing agents such as sodium borohydride $\left(\mathrm{NaBH}_{4}\right)$ and hydroxylamine hydrochloride. Vitamin $B_{2}$ is the most abundant organic cofactor found in nature, and it exists in three different redox states: fully oxidized, one-electron reduced, and fully reduced [160] (Scheme 2), as each of these redox states can present in a cationic, a neutral, or an anionic form depending on the $\mathrm{pH}$ of the solution, and all can transfer electrons [137]. 


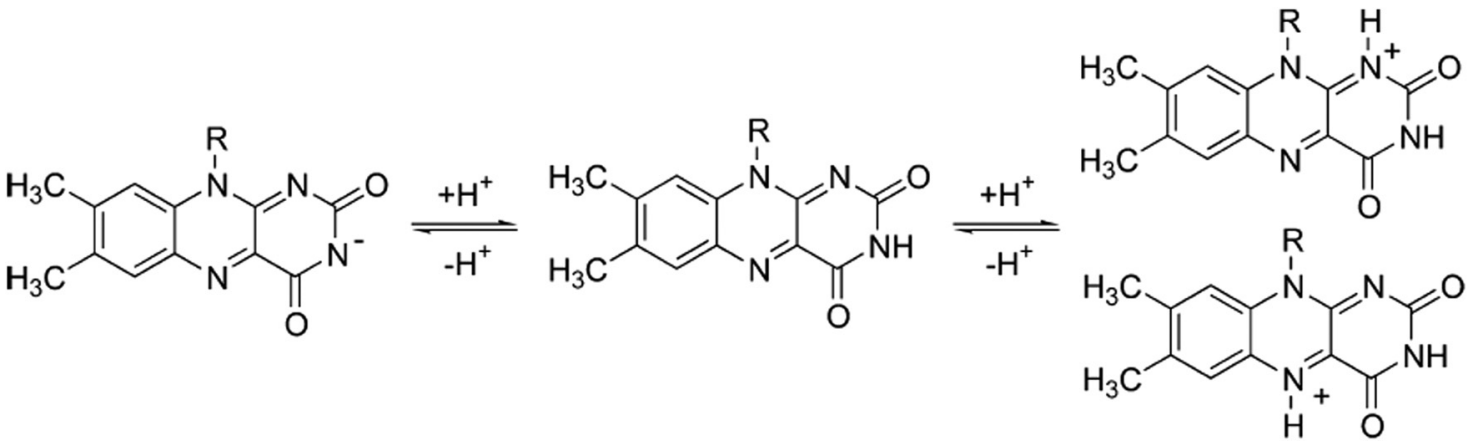

Scheme 2: Structure of the anionic (left), neutral (center), and cationic (right) vitamin $B_{2}$ species in the fully oxidized redox state ( $R=$ $\left.-\mathrm{CH}_{2}(\mathrm{CHOH})_{3} \mathrm{CH}_{2} \mathrm{OH}\right)[137,160]$.

\section{Ascorbic acid (vitamin C) and its derivatives as fundamental factors for MNP and MONPs preparation}

Vitamin C (Figure 9) is abundantly present in many natural sources, including fresh fruits and vegetables. The richest sources of ascorbic acid include Indian gooseberry; citrus fruits such as limes, oranges, and lemons; tomatoes; potatoes; papaya; green and red peppers; kiwifruit; strawberries; cantaloupes; green leafy vegetables such as broccoli; and fortified cereals, and their juices are also worthy sources of vitamin $\mathrm{C}$. Another source of vitamin C is animals. They usually produce their own vitamin $\mathrm{C}$, which is highly concentrated in the liver part [161,162]. The structure of vitamin $\mathrm{C}$ and its derivatives are given in Figure 10.

Vitamin C (vit C) or ascorbic acid (AA) is a hydrophilic molecule, which consists of six carbons, similar to glucose [109]. In the organisms, vit $C$ can be found in the reduced form (ascorbic acid or ascorbate) or in the oxidized form called dehydroascorbic acid, which<smiles>O=C1O[C@H]([C@@H](O)CO)C(O)=C1O</smiles>

Figure 9: L-Ascorbic acid molecular structure [161]. is generated from two-electron oxidation of ascorbic acid [162].

Some alterations have been done to vit $\mathrm{C}$ molecule to improve its stability. One option is to connect ionic salts to the molecule. In this sense, one of the most well-known complexes is ascorbyl 2-phosphate, which is formulated with sodium (SAP) or magnesium (MAP) salts and has hydrophilic characterization. These structures are given in Figure 10. The introduction of phosphate group at the second position of the cyclic ring of the molecule is effective against oxidation. Despite being more stable, these derivatives appear to be less permeable through the skin in comparison with ascorbic acid [163].

The nanoparticles that are generated from the natural polymers have been comprehensively used in the pharmaceutical and food industries. These systems have low toxicity and are bioconvenient and biodegradable. Ascorbic acid functions as a reducing and capping agent for the synthesis of MNPs such as silver, gold, and copper. Ascorbic acid molecules can cap or surround the particles and prevent the uncontrolled growth of the particles to micron-sized dimensions. A study by Khan et al. in 2016 reported the copper nanoparticles synthesis using ascorbic acid as the reducing agent [164]. Sun et al. reported in the Journal of Materials Science in 2009 that gold nanoparticles can be produced in inverse micelles without the addition or introduction of any reducing or capping reagent [165]. In Analytical Methods in 2014, D'souza et al. explained the use of AA-Au nanoparticles as a colorimetric probe for the detection of dichlorvos in water and wheat samples. The concentration of ascorbic acid has an influence on the aggregation induced by dichlorvos in AA-Au nanoparticles (Figure 11), and the optical property of the AA-Au nanoparticles was investigated by UV-vis spectroscopy [166]. 


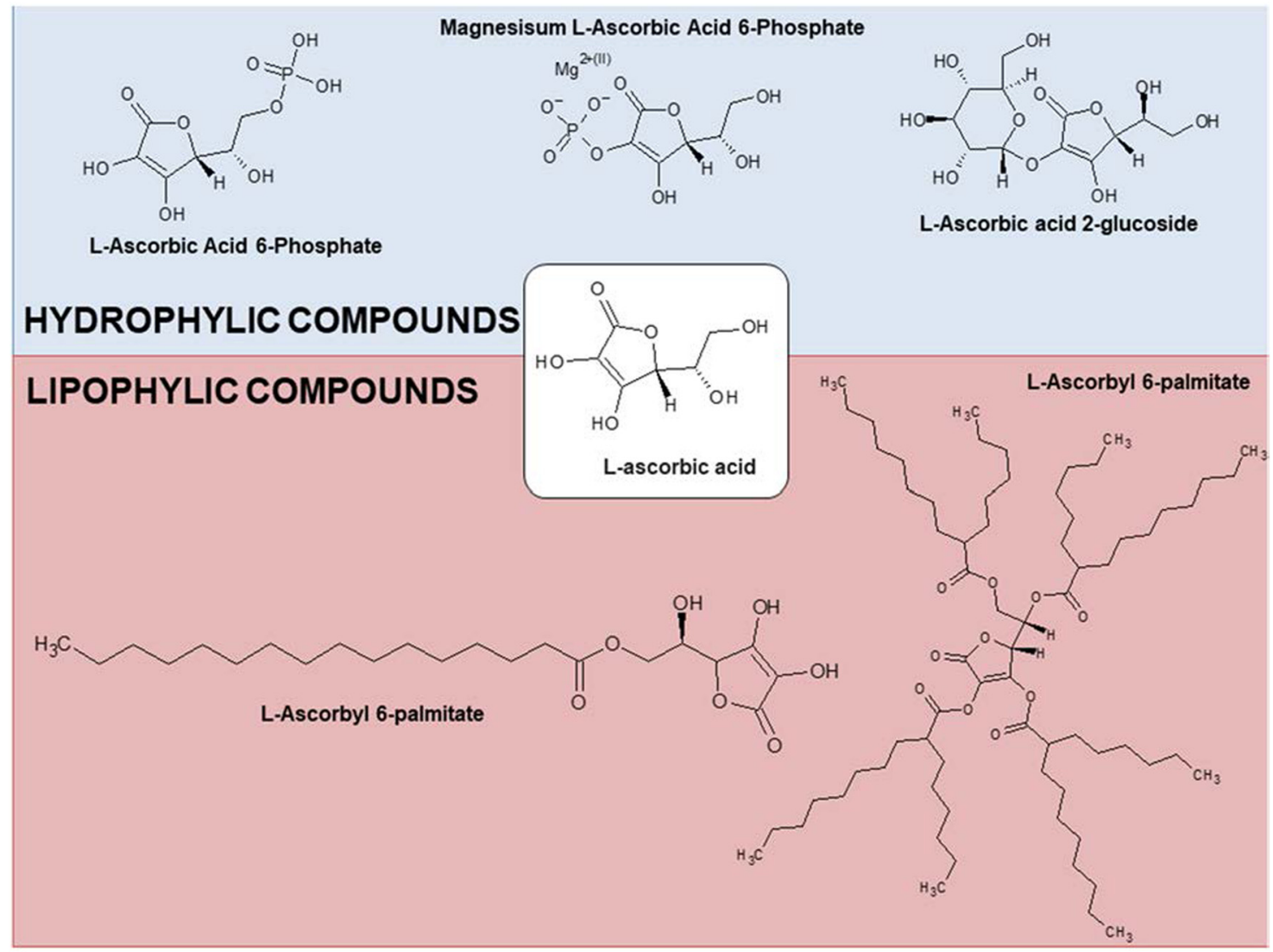

Figure 10: The structure of L-ascorbic acid and its derivatives [161,162].

\section{Phenolic compounds as substantial agent for MNP and MONPs production}

The phenolic compounds also offer protection for plants against ROS generated during photosynthesis and exposure to anthropogenic contaminants [167]. Phenolic acids have been widely used in medicine due to their powerful antioxidant activities, as they are considered phenolic derivatives with at least one functional carboxylic group. The majority of phenolic acids include larger polyphenols and other organic and structural compounds $[168,169]$. The two major categories of the natural phenolic acids are benzoic acid derivatives and cinnamic acid derivatives. The categorization is based on the number of hydroxylation sites in the aromatic ring (Figure 12) [170]. ROS and free radicals can be scavenged by the hydroxyl groups of these structures [171]. The chemical structures of both groups of phenolic acids are represented in Figure 12. Medicinal plants have large quantities of phenolic compounds as secondary metabolites. A wide range of plant-based foods and syrups contain phytochemical phenolic acid, which are well known for the antioxidant, anti-cancer, and anti-inflammatory properties [172]. Phenolic acids can be used as a reducing agent for the preparation of MNPs by a thermodynamic equilibrium approach, and nucleation is commenced by injecting the reducing agent (phenolic acids) at the metal ion supersaturation concentration, followed by the MNPs ulterior growth through progressive ion reduction [173]. The inception can be expedited by the high oxidation inclination of phenolic acids [174]. The oxidation of hydroxyl functional group of caffeic acid would present electron $\left(\mathrm{e}^{-}\right)$required for neutralizing gold ions $\left(\mathrm{Au}^{3+}\right)$, which was inspected by Hyun-soek et al. [175]. The reducing capacities of propyl gallate, ferulic acid, caffeic acid, vanillic acid, and protocatechuic acid in the presence of hydrogen tetrachloroaurate were inspected by Scampicchio et al. [176] using the UVvis spectroscopy and colorimetry methods. The phenolic acid bioreduction potential was directly linked to the number of functional hydroxyl groups, which was declared by other authors. The absorbance of phenolic 


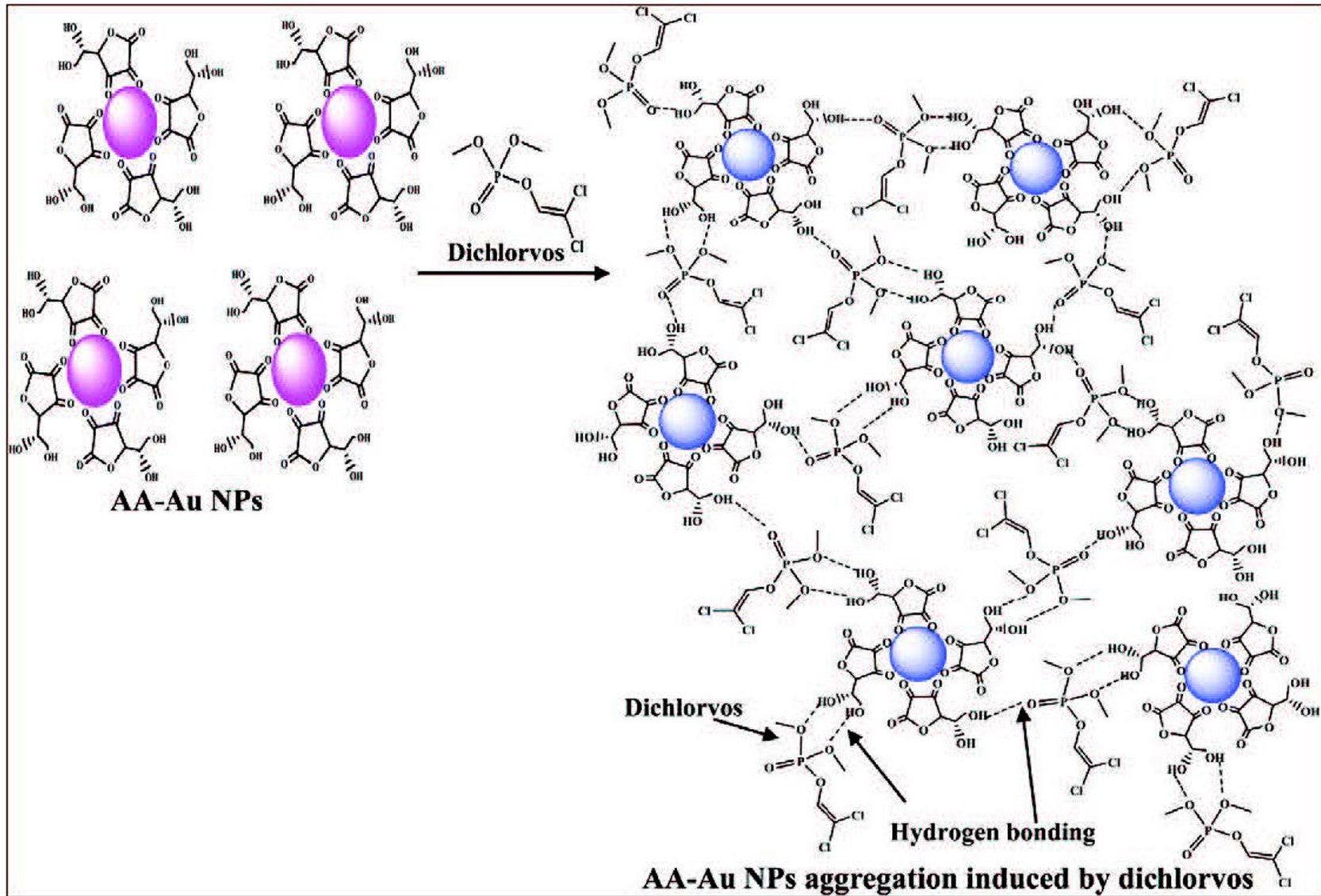

Figure 11: Detection of dichlorvos by utilizing AA-Au NPs as a colorimetric probe: an analytical process [166].

Cinnamic acid derivatives<smiles>[R2]c1cc(/C=C/C(=O)O)cc([R2])c1O</smiles>

$\mathrm{R}_{1}=\mathrm{H}, \mathrm{R}_{2}=\mathrm{H}$ mm p-coumaric acid $\mathrm{R}_{1}=\mathrm{OH}, \mathrm{R}_{2}=\mathrm{H} m$ caffeic acid $\mathrm{R}_{1}=\mathrm{OCH}_{3}, \mathrm{R}_{2}=\mathrm{H}$ m) ferulic acid $\mathrm{R}_{1}=\mathrm{OCH}_{3}, \mathrm{R}_{2}=\mathrm{OCH}_{3}$ m) sinapic acid
Benzoic acid derivatives<smiles>[R2]c1cc(C(=O)O)cc([R2])c1O</smiles>

$\left.\mathrm{R}_{1}=\mathrm{H}, \mathrm{R},=\mathrm{H} m\right)$-hydroxybenzoic acid

$\mathrm{R}_{1}=\mathrm{OH}, \mathrm{R}_{2}=\mathrm{H}$ m" protocatechuic acid

$\mathrm{R}_{1}=\mathrm{OCH}_{3}, \mathrm{R}_{2}=\mathrm{H}$ m) vanillic acid

$\mathrm{R}_{1}=\mathrm{OH}, \mathrm{R}_{2}=\mathrm{OH}$ m) gallic acid

$\left.\mathrm{R}_{1}=\mathrm{OCH}_{3}, \mathrm{R}_{2}=\mathrm{OCH}_{3} m\right)$ Syringic acid

Figure 12: The phenolic acids used for the preparation of MNPs and their main chemical structures [170].

acid attached to the MNPs surface is generated from the formation of an absorbent bond between carboxyl group and the metal atom $[177,178]$.

The metal ion chelation capability of phenolic acids such as caffeic acid and coumaric acid also participates in the nanoparticle formation process [179]. The MNPs prepared by phenolic compounds have higher stability than those prepared by other organic or inorganic reducing agents such as citrate or sodium borohydride [180], and the synthesized MNPs can be coated on the surface with protonated reducing agents such as citrate through various mechanisms based on the intermolecular interactions between the absorbed molecules and the metal surface [114]. Natural phenols with functional 

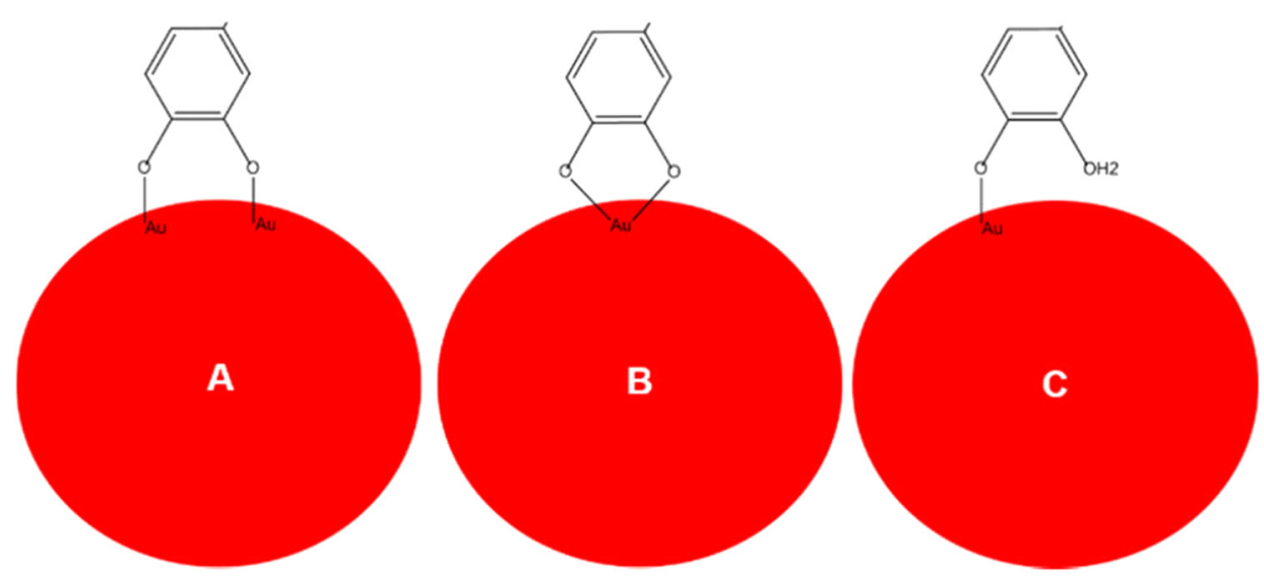

Figure 13: Schematic explanation of catechol group binding; three different configurations on the surface of the MNPs. (a) Bidentate bridging bonding, (b) bidentate chelating bonding, and (c) monodentate ester-like bonding $[183,184]$.

hydroxyl [181] and carboxyl [182] groups have protonating and absorbing capabilities and catechol group of some phenolic compounds is a perfect metal absorbing moiety. This functional group can be absorbed on the surfaces of MNPs through three different configurations including bidentate bridging bonding, bidentate chelating bonding, and monodentate ester-like bonding (Figure 13) [183,184]. Different spectroscopic techniques have been applied for studying the phenolic acid absorption on the MNPs surfaces. Although the UV-vis absorption spectroscopy technique has confirmed the phenolic acids capability of reducing metal ions, this method could not confirm the phenolic acids attachment to the surface of the prepared nanoparticles [185].

Furthermore, it is conceivable to reveal the distinctive absorbance peaks of capsaicin, cinnamic acid, gallic acid, salicylic acid, and other phenolic acids attached to the surfaces of the MNPs using the Fourier transform infrared spectroscopy technique [186-189]. Last, it is contingent to acquire the micrographs of the phenolic acids coated on the MNPs and MONPs by transmission electron microscopy (TEM) (Figure 14) [190-193]. Green chemistry through plant biomass or extract is an approach for the production of biocompatible MNPs. Specific plant or algae may be worthy due to its content of some phenolic acids compound; however, still, there is a multitude of other materials, that makes the investigation of the function of the phenolic acids compound in the spotted toxicity generated from synthesized MNPs very complicated. In general, the reported toxicity effect of the MNPs prepared using plant extract is dialectical in pieces of the literature. However,

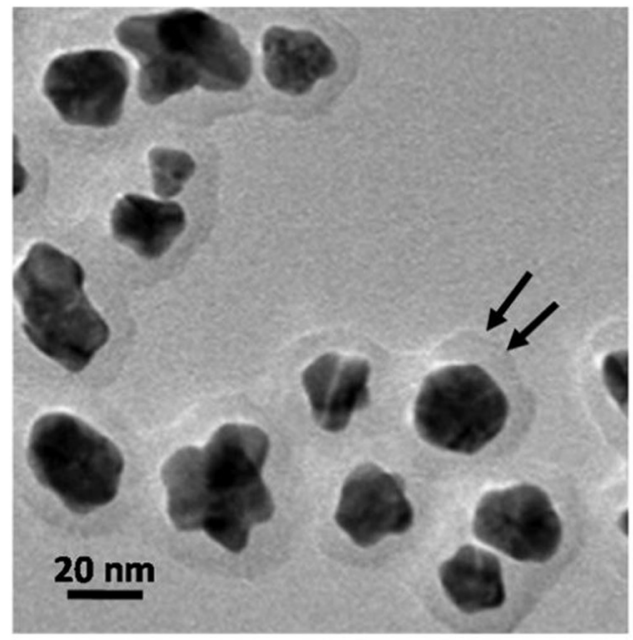

a

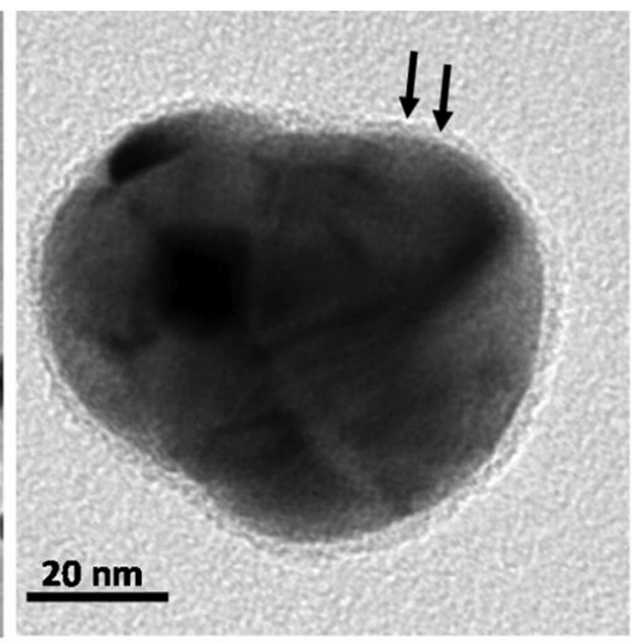

$b$

Figure 14: TEM micrographs of (a) phenolic acid-coated gold nanoparticles [190] and (b) silver/selenium alloy nanoparticles [191]. 
the MNPs that have been synthesized from plant extract have higher biocidal activity compared with the chemically synthesized nanoparticles, which was reported previously [194].

\section{Microwave heating}

Microwave (MW) technology is emanating as a substitutional energy source potent enough to fulfill chemical transformations in minutes, instead of hours or even days. In the nanomaterial preparation context, it is more pertinent when the material properties investigation depends solely on the size and shape, and the control over the synthetic methodologies is crucial. This refers to the materials growth in nanoscale is largely subordinate on the thermodynamic and kinetic barriers in the reaction as known by the reaction trajectory and is influenced by vacancies, defects, and surface reconstructions. Traditional thermal techniques are instituted on blackbody radiation conduction to boost the reaction, where the reaction vessel performs as intermediary for conveying energy from the heating mantle to the solvent and last to the reactant molecules, which can give rise to severe thermal gradients throughout the bulk solution and incomplete, nonregular reaction conditions. In the nanomaterials preparation, this has been a problematic issue where uniform nucleation and growth rates are stringent to the material quality. MW heating method can classify the heating problems in homogeneity in the classic thermal techniques as its use provides boosted reaction kinetics, and fast primary heating, and, hence, improved reaction rates culminating in clean reaction products with fast consumption of starting materials and higher yields [195].

The methodology is viable under a set of conditions even for enzymatic and biological systems. A bulk and shape-controlled noble nanostructures with different shapes such as prisms, cubes, and hexagons were synthesized via the MW-assisted spontaneous reduction of noble metal salts using an aqueous solution containing $\alpha$-D-glucose, sucrose, and maltose [136]. The ensuring nanoparticles size can be simply controlled by changing the concentration of sugars; a higher concentration offers regularly smaller size particles, which increases with minimization in the concentration of the sugars. A general method has been improved for the crosslinking reaction of poly(vinyl alcohol) (PVA) with metallic systems, such as $\mathrm{Pt}$ and $\mathrm{Cu}$, and bimetallic systems, such as Pt-In, Ag-Pt, Pt-Fe, Cu-Pd, Pt-Pd, and $\mathrm{Pd}-\mathrm{Fe}$ [196], single wall carbon nanotubes and multiwall carbon nanotubes (MWNT) and buckminsterfullerene (C-60) [197]. The formation of biodegradable CMC composite films with noble nanometals is the extension of the strategy [135], such as metal decoration and carbon nanotubes alignment in CMC by using a MWassisted approach [198], which enables the shapecontrolled bulk synthesis of $\mathrm{Ag}$ and $\mathrm{Fe}$ nanorods in poly(ethylene glycol) solutions [199]. A cleaner approach to the formation of tantalum oxide nanoparticles is optimized using the ethyl glycol-mediated pathway [200]. A newer form of the carbon-doped porous titania, which can be useful for the visible light-induced photodegradation of contaminants, has been synthesized using dextrose, a benign natural polymer [201]. The fluffy nature of the $\mathrm{TiO}_{2}$ is due to the spontaneous heating of the solvent, water, and its ulterior evaporation and combustible sugar dextrose. This general and eco-friendly protocol utilizes dextrose to create a spongy porous structure and can be extended to other transition metal oxides such as $\mathrm{ZrO}_{2}, \mathrm{Al}_{2} \mathrm{O}_{3}$, and $\mathrm{SiO}_{2}$. The noble nanocrystals undergo catalytic oxidation with monomers such as pyrrole to generate noble nanocomposites, which have potential functions in catalysis, biosensors, energy storage systems, and nanodevices. The wet chemical synthesis of $\mathrm{Ag}$ cables wrapped with polypyrrole has been carried out at room temperature without using any surfactant/capping agent and/or template [202]. The MW hydrothermal process delivers magnetic nanoferrites [203], micro-pine structured catalysts, and metal oxides with 3D nanostructures, which are obtained from facilely available metal salts [204]. These materials were synthesized from low-cost materials in water without using any reducing or capping reagent. This principle could ultimately enable the fine-tuning of the material responses to magnetic, electrical, optical, and mechanical stimuli. The particles with various well-defined morphologies, including octahedron, sphere, triangular rod, pine, and hexagonal snowflake were obtained, and the size range of 100-500 nm were acquired, as shown in Figure 15.

\section{MNPs and therapeutic proteins}

Plants has many features compared with mammalian and insect cells, as the system is completely scalable and cheap and avoids potential contamination with mammalian pathogens. Manipulated plants can be used with some chemical compounds for the biomaterials production, but they do not have the ability to generate variety of prepared polymers by utilizing current chemical polymerization techniques. Though, by prevailing the gene transfer technology, it is 

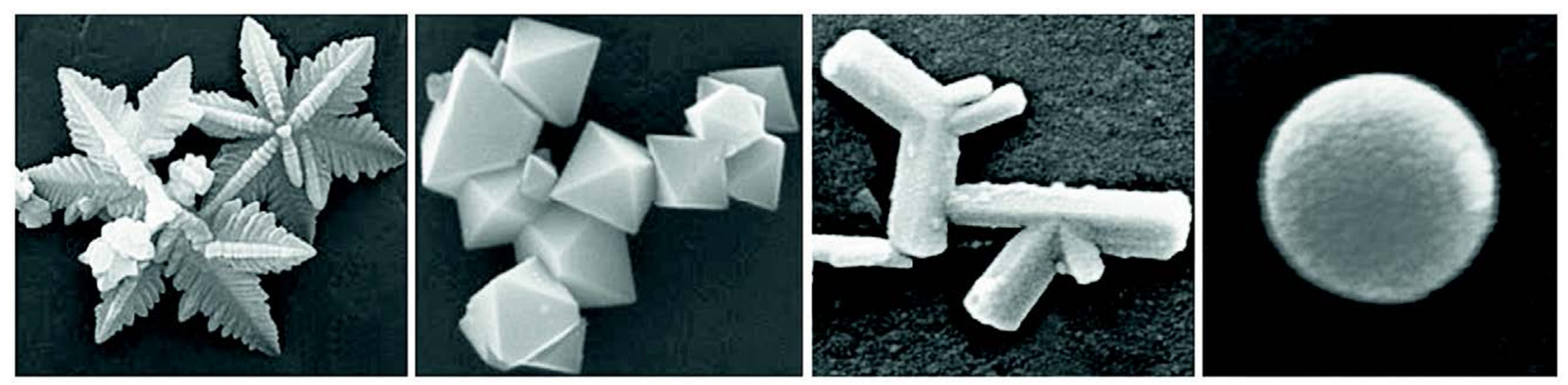

Figure 15: Well-known morphologies of metal oxides [10].

practical to recognize the compound compositions of interest and have a control over physicochemical properties and implementation which is difficult to attain, using chemical techniques [205]. A considerable advance has been achieved in many fields such as biotechnology and gene transfer. Worthy pharmaceutical compounds and antibodies were produced using transgenic plants, but because of negative public realization and the gene escape prospect danger, the full implementation of this technology was constrained. Hence, prevailed new systems have used heterogeneous proteins that depend on viral vectors, which are not produced by transgenic plants. The excellent resources for production of greener biomaterials are plants and many biomaterials like collagen, gelatin, polyhydroxyalkanoates, silk, and elastin have been highlighted [206-209]. The use of phytomedicines has been increased because of their therapeutic value when compared with allopathic medicines, as these biocompounds have fewer side effects. A better understanding of functions and kinetics of phytopharmaceuticals should aid in laying out novel drug molecules and dynamic treatments [210]. Plant extracts comprise important secondary metabolites, including alkaloids, terpenoids, phenolic acids, and flavonoids, which are the key compounds involved in the preparation of bulk metallic nanomaterials and MNPs [211]. Such metabolites are routinely used in the redox reactions to synthesize eco-friendly nanoparticles. It is well recognized that different plants, herbs, and species are the key sources of powerful antioxidants, such as phytochemical subunits present in leaves, stems, seeds, and fruits [212,213]. The plant-based nanoparticles and other nanoparticles by-products utilization is very essential for a decisive solidarity connection between plant science and nanotechnology [214,215]. The nanotechnology plays a major role in drug delivery, in which a small particle size is allowed to the arrival to the all drugs surface area and on the other hand cements fast dissolution in the blood. In addition, drug delivery is targeted in a specific characterization to a sitespecific action of the drug. Microspheres and liposomes can easily thread via sinusoidal spaces in the bone marrow and spleen compared with other systems due to their very small size. Nanoparticles increase the proteins uniformity against enzymatic decay and displayed distinction over classical methods in terms of competence and effectiveness. Drugs or other active compounds can be loaded on the engineered nanoparticles for effective targeted transfer to particular sites in an organism. Prominent efforts have been made to inspect the broad applications of the engineered nanoparticles in human systems, mainly for targeted drug delivery, cancer therapy, and treatment of different genetic disorders, which can be well classified by their functional uses [209]. Recently, Aminianfar et al. [216] realized that the toxicity of botulinum toxin type A was minimized when it was coupled with nanosilver (Ag) and intraperitoneally injected into rats. Cuscuta chinensis can be used to produce nano-sized drugs by a nanosuspension method for their antioxidant and hepatoprotective effects. Similarly, Radix salviae nanoparticles synthesized by the spray drying method have been used in the treatment of coronary heart disease and myocardial infarction [217,218]. The potential use of nanotechnology techniques leads to an increased bioactivity and bioavailability of phytomedicine by lowering the particle size, surface alteration, and trapping the phytomedicine with different nanomaterial polymers. In the future, it is indispensable to converge the new multifunctional nanomaterial designs and development and in vivo studies of their formulations for dynamic implementation in the pharmacological domain $[217,218]$.

\subsection{Phyto-nanotechnology and plant-made nanostructures}

Plant-based eco-friendly and greener nano-accesses for the assembly of nanoparticles have major features compared with the classical methods of nanoparticle preparation using toxic and hazardous materials. Plant extracts are renewable in nature and often treated in an eco-friendly aqueous 
medium. Furthermore, the reaction conditions used in the manufacture processes are mild [217-220]. Since the plant extracts and phyto-nanoproducts are cheap, non-risky, and energy efficient, they are receiving attention. Phyto-nanotechnology has a large prospect in the manufacture of different nanoparticles by using the extracts of various plant parts such as leaves, seeds, flowers, and roots [205,221]. The prepared biological nanomaterials have noble applications in the pharmaceutical industry such as novel pharmaceuticals preparation, imaging, drug delivery, diagnosis processes, and making operative nano-devices [222]. Hence, the greener production of nanoparticle is the key factor for improving new therapies to monitor different epidemic diseases [223]. The fast growth in the commercial applications of the nanomaterials is directed to an intense search for the greener pathways for the preparation of nanoparticles, particles of nanometer size, i.e., $10^{-9} \mathrm{~m}$ [224]. Improving alternative ecofriendly processes for producing nanoparticles is mandatory [225]. Researchers have prioritized their inspections to the nanomaterials biopreparation as a "bottom-up" track; various organisms could prepare nanoparticles in an ambient environment (pressure and temperature), avoiding the production of harmful agents and risky by-products [226]. Historically, nanoparticles bioproduction using plants was adduced in the early 1900s - the colloidal Ag aggregation in the organs of living organisms [227] and ion bioreduction by plant roots [228]. Also, the MNPs preparation using plant seed extracts has been presented [229], via the $\mathrm{Ag}$ nitrate reduction, including formation inside the plant cells [230]. Although a change in the color of Ag nitrate to yellow [229] or yellowish-brown [228] was considered as a signal for nano$\mathrm{Ag}$ consistency [231], the ensuring reduction products were not peculiarly analyzed [228,229]. Notably, alfalfa plant, Medicago sativa [232], with the experimental evidence of various living plants preparation [233] were used for the demonstration of well known nanoparticle preparation with ground plant biomass. Several reports have shown the potential applications of various plant parts, including leaves [234,235], seeds [236], flowers [237], fruits [238], latex [239], tuber [240], bark [241], and cultured tissues [242], to produce nanoparticles.

\section{Silver nanoparticles green synthesis by using glutathione in water using microwaves}

To remove or at least lower waste generation, there is an increased affirmation on improving green and sustainable chemical methods, as implementing sustainable methodologies in almost all sectors of chemistry, including nanomaterial preparation, requires removal of toxic reagents and solvents. The use of a multipurpose agent that acts a reducing, capping, and dispersing agent may be achieved by the choice of an environmentally benign solvent, which is one of the key issues in the green preparation of nanomaterials [243]. Silver nanoparticles have a wide range of applications in catalysis [244], electronics [245], photonics [246], optoelectronics [247], sensing [248], and pharmaceuticals [249]. The attention of the scientific society to improve more modern green preparation processes for producing these nanoparticles leads to the preparation of these particles that are powerful candidates for the surface-enhanced Raman spectroscopic studies [250]. Silver nanoparticles have been synthesized with various morphologies as well as size allocations by several pathways including $\mathrm{NaBH}_{4}$ reduction [251], polyol method [252,253], use of plant extracts [254,255], and photoreduction [256]. Majority of these processes use strongly interacting reducing agent such as sodium borohydride and hydrazine, which means they proceed via the wet chemistry methods and some of them use noxious and highly volatile organic solvents. The use of amino acids [257], vitamins [138], and other environmentally friendly biological agents in the preparation of MNPs prevents the use of toxic reducing agents. Microwave irradiation (MW) is emerging as a fast and ecofriendly procedure of heating for nanomaterials generation in conjunction with the use of these environmentally friendly reducing agents and solvents. It offers steady nucleation and growth conditions for nanomaterial preparation [199,203,258,259] through a rapid and volumetric approach and provides a fast and volumetric heating of solvents, reagents, and intermediates. The silver nanoparticles can be synthesized rapidly and easily using glutathione (GSH) as a reducing and capping agent under MW irradiation conditions in pure aqueous medium; GSH (Figure 16) was selected as a reducing agent due to its benign nature and strongly interacting thiol group, which can be utilized to reduce the metal salts. GSH is a tripeptide consisting of glutamic acid,

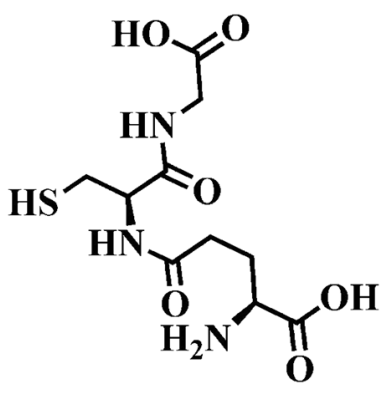

Figure 16: Molecular structure of GSH (reduced) [250]. 
cysteine, and glycine units and is an omnipresent antioxidant present in the human and plant cells. In addition to the thiol group, each GSH molecule contains amine and carboxylate groups, which offer coupling prospects for further cross-linking to other molecules of biological or sensing interest.

\section{Coffee and tea extracts to prepare silver and palladium nanoparticles at room temperature}

There are many technological applications for noble MNPs due to their widespread use and different wet chemical preparation methods have been described previously $[137,260-270]$. Due to the extraordinary properties of the synthesized metal and semiconductor nanoparticles, they attract a great interest, as they vary when they are in bulk, which is considered a modern attention in using green chemistry concepts to prepare MNPs $[135,137,196,271,272]$. For example, silver and gold nanoparticles manufactured from vegetable oil can be used in antibacterial paints [273]. Strategies to address mounting need to eco-friendly benign solvents, biodegradable polymers, and nontoxic chemicals were built. In the synthesis of MNPs by the reduction of corresponding metal ion salt solutions, there are three areas of opportunity to engage in green chemistry:

(i) Solvent selection.

(ii) The reducing agent used.

(iii) The capping agent (or the dispersing agent) used.

Increased interest has been given to distinguish ecofriendly materials that are multifunctional. The caffeine/ polyphenols used as both a reducing and capping agent for the synthesis of Ag and Pd nanospheres; due to its large water solubility, low toxicity, and biodegradability, caffeine is the most widespread and effective robust drug in the universe. In North America, $80-90 \%$ of adults use caffeine. However, there are no reports on the synthesis of noble metals using caffeine, which acts a critical part in many medical applications. For the first time, the noble metals such as Ag and Pd were prepared using tea/coffee extract, as caffeine/polyphenols can form complexes with metal ions in solution and reduce them to the corresponding metals. Different brands of tea and coffee such as Sanka coffee, Bigelow tea, Luzianne tea, Starbucks coffee, Folgers coffee, and Lipton tea were used to prepare nanoparticles by the single-pot method, which uses no surfactant, capping agent, and/or template, and the resulted nano- particles were in the size range of 20-60 $\mathrm{nm}$ and crystallized in face centered cubic symmetry [71].

\section{Green and controlled synthesis of gold and platinum nanomaterials using vitamin $\mathbf{B}_{\mathbf{2}}$ : nanospheres, wires, and rods density-assisted self-assembly}

The highly structured nanoparticles assembly preparation such as wires, rings, and superlattices is being inspected thoroughly [274-286]. The major challenge is how to control the particle size and shape during preparation, and some physical and solid state chemical methods have been improved to manufacture semiconductors, metal nanowires, nanobelts, and nanodots [287]. Nowadays, there are various method for making rods with some approaches [288], pH-dependent assembly of gold nanorods [289]. The improvement of bulk solution preparation processes that provide shape control is of fundamental importance if the full labor of these materials is to be observed, as these solution-based processes are usually proceeded at elevated temperatures and often confer poor yields of the desired materials with adequate shape. The reaction medium density that cements the noble MNPs self-assembly into spheres, nanowires, and nanorods in the presence of vitamin $\mathrm{B}_{2}$ (a crucial reaction parameter). There is an increased assertion on the preparation of nanoparticles using greener processes [290]. This environmentally benign approach offers an easy access to produce multiple shaped noble nanostructures, which could have prevalent technological and medicinal applications. The preparation and self-assembly was executed by reacting the competent metal salts with vitamin $B_{2}$ dissolved in solvents of varying densities, such as ethylene glycol $(\rho=1.113)$, acetic acid $(\rho=1.049), N$-methyl pyrrolidine $(\rho=$ 1.03), water $(\rho=0.998)$, isopropanol (i-PrOH, $\rho=0.790)$, acetone $(\rho=0.790)$, and acetonitrile (MeCN, $\rho=0.782)$ at room temperature [137].

Vitamin $B_{2}$ reduction potential is $-0.3 \mathrm{~V}$ vs standard calomel electrode $\left(\mathrm{SEC}^{10}\right)$, which is adequate to reduce $\mathrm{Au}^{3+}$ to $\mathrm{Au}^{0}$, whose reduction potential is $1.50 \mathrm{~V}$ vs SCE, which is similar to that of $\mathrm{Pt}$ (reduction potential is $1.20 \mathrm{~V}$ ) and other noble metals such as Pd (reduction potential $0.915 \mathrm{~V}$ ) and $\mathrm{Ag}$ (reduction potential $0.80 \mathrm{~V}$ ). $\mathrm{Au}$ and $\mathrm{Pt}$ nanoparticles were prepared with vitamin $B_{2}$ [291] by the following steps: 
1. Complexation with $\mathrm{Au}$ and Pt metal salts.

2. Simultaneous reduction of $\mathrm{Au}$ and Pt metal salts and capping formation with oxidized vitamin $\mathrm{B}_{2}$.

3. Self-assembly of nanoparticles to form spheres, nanowires, and nanorods.

\section{Green preparation of $\mathrm{Ag}, \mathrm{ZnO}$, and $\mathrm{Ag} / \mathrm{ZnO}$ nanoparticles for manufacturing clinical antimicrobial wound-healing bandages}

Open wounds are due to the loss of skin integrity and subcutaneous layers, giving rise to visible external bleeding, which are prone to infection, and germs can enter fastly to the deeper layers of the skin, access the lymph nodes, and squander throughout the body. Thus, all scars should be cleaned and covered completely and the coating should be uniform. Appropriate wound coating helps manage bleeding, inhibits contamination via blood absorption and secretion from the wound, and recuperate the wound rapidly [292]. A bandage impregnated with alcohol or Betadine is usually used to inhibit the prosperity and proliferation of pathogens in the wound. Betadine (povidone-iodine) and alcohol are robust microbicidal solutions, which can destroy all types of bacteria, viruses, fungi, and other microorganisms [293]. Lavelle et al. [294] presented that the absorption of iodine led to an unclarified anomaly and renal failure in some patients. This solution has no harmful effect if used on the dry skin, but if it is applied on the wound, it will lead to allergic reaction in some people [295] and absolutely retard the healing of the wound, and the scars will stay, and the solution should not be used on wounds such as burns or surgical areas. Using Betadine to treat the wounds of skin of pregnant mother hurt the baby and sanitization of umbilical cord with iodine as well as other agents leads to hypothyroidism in infants [296]. The use of alcohol also brings about intense agitation and can destroy the healthy cells. The problem with antibiotics is that the resistance of renitent strains and microbial strains is restricted to one or few types of antibiotics. Renitent wounds grow faster if the feeding tissue get infected and can even lead to patient death. Managing renitent strains and preventing epidemics has become particularly complicated when intense unexpected crises such as earthquakes, floods, or large fires occur, that lead to a large numbers of patients injured with supercritical and profound wounds in the hospitals. Because of the obvious misuse of betadine, alcohol, and the multidrug resistant to microbes, global interest of research studies is now focused on the alternative newer antimicrobials to use it periodically to inhibit the epidemic of the microbial strains.

We visualized to manage microbial strains and wounds remediation, particularly surgical, fungal, or diabetic wounds, by using nanoparticle-based bandages; nanoparticles are one-dimensional particles with size ranging from 1 to $100 \mathrm{~nm}$ [297]. The antimicrobial activity of silver (Ag) and zinc oxide $(\mathrm{ZnO})$ has been boosted on a nanoscale, and they can be utilized to manage different human and animal pathogens with nanotechnology [298-307]. The material dimensions and nanoparticles capping are also key factors influencing the materials characteristics, as polyphenolic compounds, sugars, and epicatechin present in plant extracts [10] and tea or coffee are fundamentally responsible for the reduction of salts and capping of ensuring nanoparticles. Microbes act as an adequate substitute for nanoparticles generation; greener preparation of nanoparticles by bacteria and fungi has been considered [308-311]. The bacterial strains Acinetobacter baumannii and Pseudomonas aeruginosa mainly cause the infection in burn wounds. Due to these pathogenic strains resistance to popular antibiotics and the biofilms generation, finding new antimicrobials is now mandatory, so the trial to manufacture clinical antibacterial bandage is growing faster. Over the past years, significant efforts have been made to manufacture antibacterial coatings on different surfaces of the objects, such as clothing and medical accommodation merging $\mathrm{Ag}$ nanoparticles. $\mathrm{Ag}$ and $\mathrm{ZnO}$ nanoparticles were prepared by an ecofriendly procedure because of the exigency of coping with drugresistant pathogens and offering modern antimicrobial coatings for operative ulcers remediations, as Ag and $\mathrm{ZnO}$ nanoparticles produced via greener preparation were used for the manufacture of clinical nanoparticlebased antimicrobial wound remediations. Besides their composition and structure [312,313], Ag and $\mathrm{ZnO}$ nanoparticles are widely used in different fields such as medicine, pharmacy, physics, and chemistry [314,315], and they are highly esteemed by the researchers for their perfect conductivity, chemical stability, and catalytic, photonic, optoelectronic, and antioxidant characteristics. In biological research, $\mathrm{Ag}$ and $\mathrm{ZnO}$ nanoparticles have been used as antibacterial factors and in biosensors 
[316-321], and silver has been used in wound care for hundreds of years [322], with the nanotechnology improvement, the generation of $\mathrm{Ag}$ and $\mathrm{ZnO}$ nanoparticles and their use as a potent antibacterial material has been suggested. Different physical, biological, and chemical procedures, including laser abrasion, chemical reduction, and electrochemical recovery, have been proposed for nanoparticle preparation. The disadvantages of these processes are use of toxic reducing agents and higher energy consumption, which increases effective hazards to human health and the environment, and the manufacture on an industrial scale is overall forbidden as well. The biological preparation of nanoparticles with low energy exhaustion and cost is an attractive approach because of the higher costs of their chemical preparation and the increased bacterial resistance to antibiotics. Thus, phytochemical processes using the natural antioxidants have been improved to manufacture environmentally friendly and high-cost nanoparticles.

\section{African traditional beers brewed with sorghum malt}

Sorghum is a drought-tolerant crop with a pivotal role in the livelihoods of millions of people in marginal areas. The genetic structure of this varied crop in Africa has been investigated. On the continent broad scale, there are three main sorghum inhabitants (central, southern, northern). Sorghum, not similar hardly, is very well modernized to the semi-arid and sub-tropical conditions predominant over majority of the African countries [323]. Such hardly, sorghum belongs to the grass family Gramineae. In Africa, sorghum grain is the main cereal crop used to produce the classical "opaque" beers [324,325]. However, only particular sorghum varieties (e.g., red grain) are principally used to generate sorghum beers. These beers are known ikigage in Rwanda [326], tchoukoutou in Benin and Togo [327], dolo in Burkina Faso [328], pito or burkutu in Nigeria and Ghana [329,330], amgba in Cameroon [331,332], doro or chibuku in Zimbabwe [333], merissa in Sudan [334], mtamain Tanzania [335], bili bili in Chad [336], and Kaffir in South Africa. Classical sorghum beer producing processes basically include malting, drying, milling, souring, boiling, mashing, and alcoholic fermentation; but differences may happen based on the geographic localization [337]. These beer types vary from European lager types in the fact that lactic fermentation also occurs during sorghum beer processing. Besides, African traditional sorghum beer is used while it is still fermenting, and the drink contains large amounts of fragments of insoluble materials [338].

These fractions are fundamentally starch residues and dextrins that are not digested during mashing and fermentation [339]. Sorghum beers have very little resemblance in appearance to Western beer made with barley. However, some research studies have proposed that the use of sorghum malt (instead of barley malt) in lager-beer brewing is out of the way to manage due to some inseparable problems (enzymes, starch characteristics, polyphenols) associated with sorghum [340-342]. Numerous studies on the microbiological and biochemical properties of the classical sorghum beers and their engineering have been carried out and reported in various African countries. A diverse yeast and lactic acid bacterial flora were found in African sorghum beers, although Saccharomyces cerevisiae and heterofermentative Lactobacillus usually predominate [343-345]. The traditional African sorghum beers are very rich in calories, B-group vitamins including thiamine, folic acid, riboflavin, and nicotinic acid, and essential amino acids. The beers are wasted at different celebrations and African ceremonies (e.g., marriage, birth, baptism, and designate a fountain of economic return for the female). However, in most of the African countries, the traditional sorghum beers are less appealing than Western beers brewed with barley malt due to their poor hygienic quality, low ethanol content, organoleptic variation, and dissatisfying preservation [346].

\section{Comparison between classical chemistry and green chemistry for MNPs and MONPs synthesis}

The next years will prove the importance of green synthesis methods for MNPs and MONPs production because they are not only easy to execute, fast, and cheap but also less toxic and environmentally friendly [347,348], as shown in Figure 17 [41].

\section{Conclusions}

The development of nanoformulations and their numerous applications make the green preparation of 


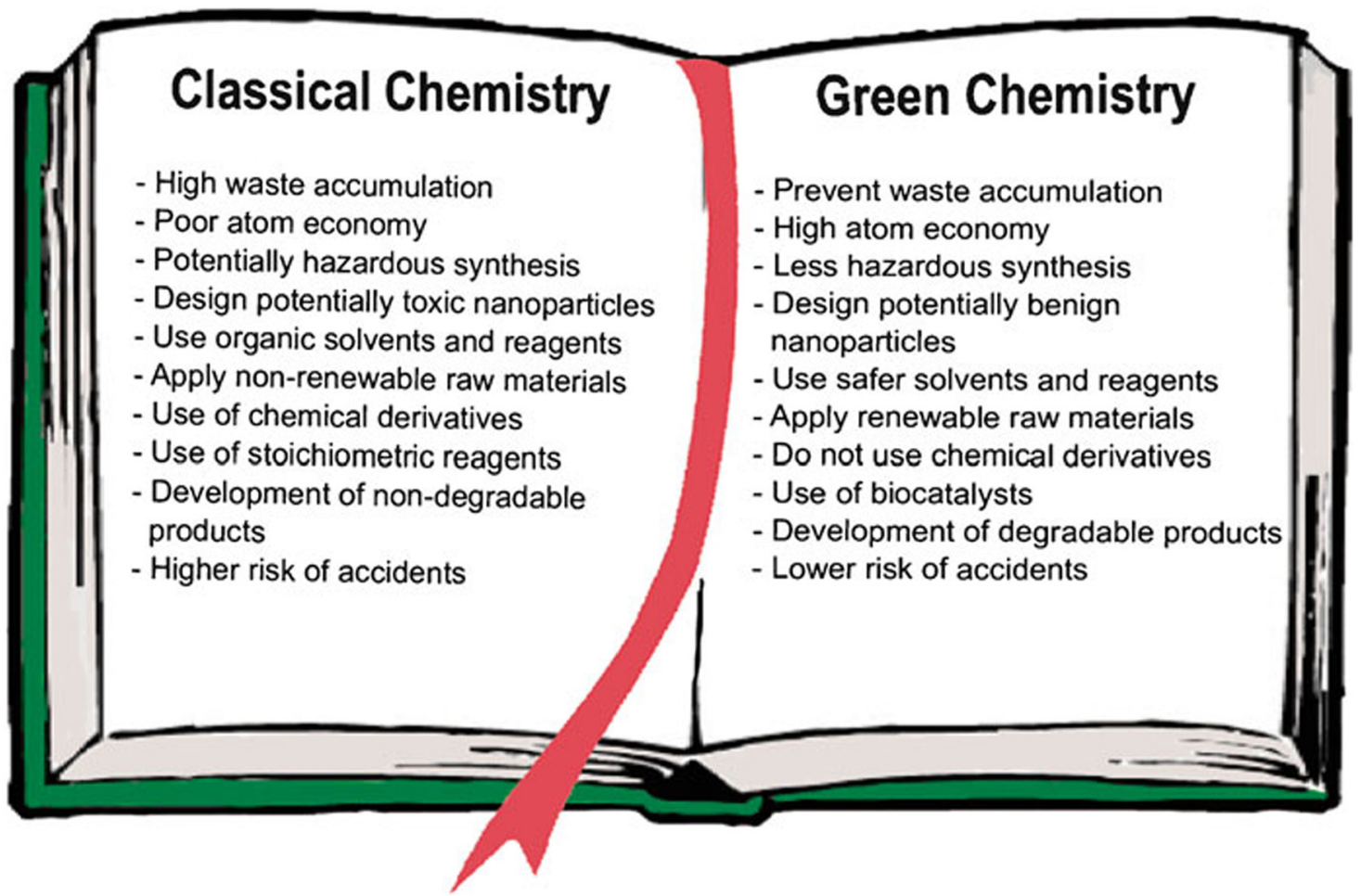

Figure 17: Comparison of the concepts and repercussions of traditional chemistry and green chemistry [41].

MNPs and MONPs hopeful and favorable area for different studies. The factors that affect the green synthesis of MNPs and MONPs from plant extracts, especially plant leaf extracts, distinctive kinetics, and nanoparticles production mechanism are still not well comprehensively understood, despite their several advantages like toxicity reduction ability, and the ease of the process execution, which make it an extensively utilized source for nanoparticle synthesis with effective, extremely eclectic, comparatively cheap, conventional and "historically secure" reducing agent, that was used for many years to prepare different organic molecules and compounds successfully. The whole green synthesis of nanoparticles requires incorporation of other more secure, sustainable, and credible reducing and capping agents, and finally avoiding the use of hazardous chemicals such as $\mathrm{NaBH}_{4}$ and hydrazine. The engineered green nanoparticles are used in many applications such as biomedicine; biology; materials science; electronics; biosensors; pharmaceutical, food, and cosmetic industries; and environmental remediation scope. For example, beet juice is used as a reducing and capping agent for the preparation MNPs such as $\mathrm{Ag}, \mathrm{Au}, \mathrm{Pt}$, and $\mathrm{Pd}$ nanoparticles, which are capped with organics by the fast microwave-supported green procedure. The Ag nanoparticles prepared by beet juice display higher catalytic activity and toughness than those synthesized by $\mathrm{NaBH}_{4}$ by the reduction of 4-nitrophenol to 4-aminophenol due to organic capping and better stampede. There is a fast and green treaty for silver nanoparticles preparation as well as other noble metals using glutathione, a benign antioxidant, which renders as both a reducing and capping agent, which means the full process was carried out in pure water without utilizing any toxic reagents or organic solvents. The silver nanoparticles ranging in size from 5 to $10 \mathrm{~nm}$ were prepared under MW irradiation conditions. It has been produced within $30-60 \mathrm{~s}$ at a power level as low as $50 \mathrm{~W}$. The MW power influence on the morphology of ensuring silver nanoparticles is examined for the green and sustainable process, which is adjusted for the palladium, platinum, and gold nanoparticles synthesis. The $\mathrm{Ag}$ and Pd nanoparticles was synthesized using coffee and tea extracts by an eco-friendly, one-step procedure by the reduction of corresponding metal ions in tea and coffee extracts without adding any special capping agents at room temperature, which is considered a greener approach to different medicinal as well as technological applications. The green and controlled synthesis of $\mathrm{Au}$ and Pt nanoparticles using vitamin $\mathrm{B}_{2}$ was carried out as follows:

1. A high yield, room temperature, density-assisted selfassembly of $\mathrm{Au}$ and Pt nanospheres, nanowires, and 
nanorods using vitamin $B_{2}$ in various solvent media, thus providing new chances in many applications, like catalysis, antibacterial coatings, and fuel cell membranes.

2. A procedure that functions without any special capping or dispersing agent, nor any polymer as a coating agent.

3. The formation of multiple $\mathrm{Au}$ and $\mathrm{Pt}$ shapes and reliance of their self-assembly on the density of the solvent used. The particles will form particular spheres as the density increases, and the particles will self-assemble to produce nanorods and nanowires with a decrease in density.

4. The environmentally benign and general approach may manage different medicinal and technological implementation and is extended to other noble metals such as $\mathrm{Ag}$ and $\mathrm{Pd}$. The main advantages of the greener preparation methods are their cheapness and the antimicrobial nanoparticles synthesis easiness using local plant extracts without the need for a toxic chemical reducing agent, and additional capping agents, as it offered bandages with high antibacterial activity, that were impregnated with $\mathrm{Ag}$ and $\mathrm{ZnO}$ nanoparticles. The bandages covered with Ag nanoparticles liquid solution have more antimicrobial effect than that of $\mathrm{ZnO}$ and mixed $\mathrm{Ag} / \mathrm{ZnO}$ nanoparticles; however, this variation is not important. After continuous clinical attempts and examination of the possible side effects of the $\mathrm{Ag}$ and $\mathrm{ZnO}$ nanoparticles, these antibacterial bandages can be probably used for remediating and coating contagion-critical wounds such as diabetic wounds or burns, so the local resources can be mobilized dynamically in improving countries, thus classified local troubles using new nanotechnology. The traditional sorghum beers have a sociocultural and nutritional value in Africa. Compared with the brewing of European beer with barely, the brewing of classical sorghum beer is characterized by the complexity of the malting operation, the speed and short time of alcoholic fermentation, and the presence of lactic fermentation. In Africa, the association of sorghum with other cereals (e.g., Eleusine coracana, Pennisetum glaucum, and sweet potato) available in Africa could solve the problem of the lack of $\beta$-amylase in sorghum malt and offer tools to avoid the use of the commercial enzymes and barely malt. The presence of unidentified microorganisms from the classical leaven makes the fermentation operation difficult to manage and produces the products of variable quality. The use of starter cultures appears to be a good method to reduce the organoleptic differences and to reduce the risk of contamination with pathogenic organisms. The current differences in the manufacturing operations of African classical sorghum beer could be incorporated into the development of a larger variety of sorghum beers in Africa.

Managing the gap between different studies will boost the green synthesis of nanoparticles from plant leaf extracts, especially flavonoids, vitamin $B_{2}$, ascorbic acid (vitamin $\mathrm{C}$ ), and phenolic compounds, which are all the main tools for MNP and MONPs preparation; as an auspicious process for non-toxic nanoparticles production, so the researchers must keep in their mind that:

1. The bioreduction mechanism, nucleation, growth, and stabilization of MNPs and MONPs by using plant extracts should be comprehend by them and their task to execute this implementation in a satisfying way, all the development concerning differences and alterations should be taken into consideration in depth, not just performing the process as a whole.

2. MNPs and MONPs synthesis from plant extracts is dependable, efficacious, foreseeable, scalable, reproducible, and safe to be applied through many fields, so they must find ingenious solutions to all the affronts they will meet to open new horizons.

\section{References}

[1] Hutchison JE. Greener nanoscience: a proactive approach to advancing applications and reducing implications of nanotechnology. ACS Nano. 2008;2(3):395-402. doi: 10.1021/ nn800131j.

[2] Xia T, Li N, Nel AE. Potential health impact of nanoparticles. Annu Rev Public Health. 2009;30:137-50. doi: 10.1146/ annurev.publhealth.031308.100155.

[3] Eckelman MJ, Zimmerman JB, Anastas PT. Toward green nano. J Ind Ecol. 2008;12:316-28. doi: 10.1111/j.15309290.2008.00043.x.

[4] Roco MC. International strategy for nanotechnology research. J Nanopart Res. 2001;3:353. doi: 10.1023/ A:1013248621015.

[5] Nanoscience and nanotechnologies: opportunities and uncertainties. The Royal Society and The Royal Academy of Engineering. 2004. p. 19, http://www.nanotec.org.uk/ finalReport.htm.

[6] Kandlikar M, Ramachandran G, Maynard A, Murdock B, Toscano W. Health risk assessment for nanoparticles: a case for using expert judgment. J Nanopart Res. 2007;9:137-56. doi: 10.1007/s11051-006-9154-x.

[7] Wardak A, Gorman ME, Swami N, Rejeski D. Environmental regulation of nanotechnology and the TSCA. IEEE Technol 
Soc Mag. 2007;26:48-56. doi: 10.1109/

MTAS.2007.4295056.

[8] Monica JC, Heintz ME, Lewis PT. The perils of pre-emptive regulation. Nat Nanotechnol. 2007;2:68-70. doi: 10.1038/ nnano.2007.15.

[9] Owen R, Handy R. Viewpoint: formulating the problems for environmental risk assessment of nanomaterials. Env Sci Technol. 2007;41:5582-8. doi: 10.1021/es072598h.

[10] Rajender SV. Greener approach to nanomaterials and their sustainable applications. Curr Op Chem Eng.

2012;1(2):123-8. doi: 10.1016/j.coche.2011.12.002.

[11] Dahl JA, Maddux BLS, Hutchison JE. Toward greener nanosynthesis. Chem Rev. 2007;107(6):2228-69. doi: 10.1021/cr050943k.

[12] Bonatto CC, Silva LP. Higher temperatures speed up the growth and control the size and optoelectrical properties of silver nanoparticles greenly synthesized by cashew nutshells. Ind Crop Prod. 2014;58:46-54. doi: 10.1016/ j.indcrop.2014.04.007.

[13] Quester K, Avalos-Borja M, Vilchis-Nestor AR, CamachoLópez MA, Castro-Longoria E. SERS properties of different sized and shaped gold nanoparticles biosynthesized under different environmental conditions by Neurosporacrassa extract. PLOS One. 2013;8(10):1-8. doi: 10.1371/ journal.pone.0077486.

[14] Yehia M, Labib S, Ismail SM. Structural and magnetic properties of nano- $\mathrm{NiFe}_{2} \mathrm{O}_{4}$ prepared using green nanotechnology. Physica B Condens Matter. 2014;446:49-54. doi: 10.1016/j.physb.2014.04.032.

[15] Sharma VK, Yngard RA, Lin Y. Silver nanoparticles: green synthesis and their antimicrobial activities. Adv Colloid Interface Sci. 2009;145(1-2):83-96. doi: 10.1016/j.cis.2008.09.002.

[16] Nadagouda MN, Varma RS. Risk reduction via greener synthesis of noble metal nanostructures and nanocomposites. Nato Sci Peace Secur. 2009;3:209-17. doi: 10.1007/ 978-1-4020-9491-0_15.

[17] Raveendran P, Fu J, Wallen SL. Completely “Green” synthesis and stabilization of metal nanoparticles. J Am Chem Soc. 2003;125(46):13940-1. doi: 10.1021/ja029267j.

[18] Murphy CJ, Sau TK, Gole AM, Orendorff CJ, Gao J, Gou L, et al. Anisotropic metal nanoparticles: synthesis, assembly, and optical applications. J Phys Chem B. 2005;109(29):13857-70. doi: 10.1021/jp0516846.

[19] Narayanan R, El-Sayed MA. Catalysis with transition metal nanoparticles in colloidal solution: nanoparticle shape dependence and stability. J Phys Chem B. 2005;109(26):12663-76. doi: 10.1021/jp051066p.

[20] McBrain SC, Yiu HH, Dobson J. Magnetic nanoparticles for gene and drug delivery. Int J Nanomed. 2008;3(2):169-80. PMID:18686777, PMCID: PMC2527670.

[21] Liao H, Nehl CL, Hafner JH. Biomedical applications of plasmon resonant metal nanoparticles. Nanomedicine. 2006;1(2):201-8. doi: 10.2217/17435889.1.2.201.

[22] Llorens A, Lloret E, Picouet PA, Trbojevich R. Metallic-based micro and nanocomposites in food contact materials and active food packaging. Trends Food Sci Tech. 2012;24(1):19-29. doi: 10.1016/j.tifs.2011.10.001.

[23] Lazarides AA, Kelly KL, Jesen TR, Schatz GC. Optical properties of metal nanoparticles and nanoparticle aggregates important in biosensors. J Mol Struct Theochem.
2000;529(1-3):59-63. doi: 10.1016/S0166-1280(00) 00532-7.

[24] Rai M, Yadav A, Gade A. Silver nanoparticles as a new generation of antimicrobials. Biotechnol Adv. 2009;27(1):76-83. doi: 10.1016/j.biotechadv.2008.09.002

[25] Wiederrecht GP, Wurtz GA, Hranisavljevic J. Coherent coupling of molecular excitons to electronic polarizations of noble metal nanoparticles. Nano Lett. 2004;4(11):2121-5. doi: $10.1021 /$ nl0488228.

[26] Singh J, Dutta T, Kim KH, Rawat M, Samddar P, Kumar P. Green synthesis of metals and their oxide nanoparticles: applications for environmental remediation. J Nanobiotechnol. 2018;16(84):1-25. doi: 10.1186/s12951018-0408-4.

[27] Nath D. Safer nanoformulation for the next decade. Green Process Nanotechnol. 2015;9(12):327-52. doi: 10.1007/9783-319-15461-9_12.

[28] Bystrzejewska-Piotrowska G, Golimowski J, Urbana PL. Nanoparticles: their potential toxicity, waste and environmental management. Waste Manage. 2009;29(9):2587-95. doi: 10.1016/j.wasman.2009.04.001.

[29] Nagajyothi PC, Tvm S. Green synthesis of metallic and metal oxide nanoparticles and their antibacterial activities. Green Process Nanotechnol. 2015;9(4):99-117. doi: 10.1007/9783-319-15461-9 4

[30] Gholami-Shabani M, Gholami-Shabani Z, ShamsGhahfarokhi M, Jamzivar F, Razzaghi-Abyaneh M. Green nanotechnology: biomimetic synthesis of metal nanoparticles using plants and their application in agriculture and forestry. Nanotechnology an agricultural paradigm. Springer Int. 2017;8(8):133-75. doi: 10.1007/978-81-10-4573-8_8.

[31] Makarov VV, Love AJ, Sinitsyna OV, Makarova SS, Yaminsky IV, Taliansky ME, et al. "Green” nanotechnologies: synthesis of metal nanoparticles using plants. Acta Naturae. 2014;6(1):35-44. PMID:24772325 PMCID:PMC3999464.

[32] Bystrzejewska-Piotrowska G, Golimowski J, Urbana PL. Nanoparticles: their potential toxicity, waste and environmental management. Waste Manage. 2009;29(9):2587-95. doi: 10.1016/j.wasman.2009.04.001.

[33] Gericke $M$, Pinches A. Biological synthesis of metal nanoparticles. Hydrometallurgy. 2006;83(1-4):132-40. doi: 10.1016/j.hydromet.2006.03.019.

[34] Lenerdão EJ, Freitag RA, Dabdoub MJ, Batista ACF, Silveira CC. Green chemistry - the 12 principles of green chemistry and it insertion in the teach and research activities. Quim Nova. 2003;26(1):123-9. doi: 10.1590/ S0100-40422003000100020.

[35] Tang SY, Bourne RA, Smith RL, Poliakoff M. The 24 principles of green engineering and green chemistry: "Improvements productively”. Green Chem. 2008;10:268-9. doi: 10.1039/ B719469M.

[36] Anastas P, Eghbali N. Green chemistry: principles and practice. Chem Soc Rev. 2009;39:301-12. doi: 10.1039/B918763B.

[37] Rajawat S, Qureshi MS. Electrolytic deposition of silver nanoparticles under "Principles of Green Chemistry". Arab J Sci Eng. 2014;39(1):563-8. doi: 10.1007/s13369-013-0879-4.

[38] Srivastava P, Bragança JM, Ramanan SR, Kowshik M. Synthesis of silver nanoparticles using haloarchaeal isolate Halococcus salifodinae BK3. Extremophiles. 2013;17(5):821-31. doi: 10.1007/s00792-013-0563-3. 
[39] El-Said WA, Cho H, Yea C, Choi J. Synthesis of metal nanoparticles inside living human cells based on the intracellular formation process. Adv Mater Interfaces. 2014;26(6):910-8. doi: 10.1002/adma.201303699.

[40] Senapati S, Ahmad A, Khan MI, Sastry M, Kumar R. Extracellular biosynthesis of bimetallic $\mathrm{Au}-\mathrm{Ag}$ alloy nanoparticles. Small. 2005;1(5):517-20. doi: 10.1002/ smll.200400053.

[41] Silva LP, Reis I, Bonatto CC. Green synthesis of metal nanoparticles by plants: current trends and challenges. Green Process Nanotechnol. 2015;9(9):327-52. doi: 10.1007/978-3-319-15461-9_9.

[42] Iravani S. Green synthesis of metal nanoparticles using plants. Green Chem. 2011;10:2638-50. doi: 10.1039/ C1GC15386B.

[43] Kumar V, Yadav SK. Plant mediated synthesis of silver and gold nanoparticles and their applications. J Chem Technol Biotechnol. 2009;84(2):151-7. doi: 10.1002/jctb.2023.

[44] Marchiol L. Synthesis of metal nanoparticles in living plants. Italian J Agron. 2012;7(37):274-82. doi: 10.4081/ ija.2012.e3732.

[45] Lakshmi KR, Sri Venkata NP, Girija SG, Veerabhadra SP, Venkata RMK. A review on anti-bacterials to combat resistance: from ancient era of plants and metals to present and future perspectives of green nano technological combinations. Asian J Pharm Sci. 2019;7:1-18. doi: 10.1016/ j.ajps.2019.03.002.

[46] Kharissova OV, Dias HV, Kharisov BI, Pérez BO, Pérez VM. The greener synthesis of nanoparticles. Trends Biotechnol. 2013;31(4):240-8. doi: 10.1016/j.tibtech.2013.01.003.

[47] Nath D, Banerjee P. Green nanotechnology - a new hope for medical biology. Env Toxicol Pharmacol. 2013;36(3):997-1014. doi: 10.1016/j.etap.2013.09.002.

[48] Jha AK, Prasad AKJ, Prasad K, Kulkarni AR. Plant system: nature's nanofactory. Colloids Surf B Biointerfaces. 2009;73:219-23. doi: 10.1016/j.colsurfb.2009.05.018.

[49] Shao Y, Jin Y, Dong S. Synthesis of gold nanoplates by aspartate reduction of gold chloride. Chem Commun. 2004;9:1104-5. doi: 10.1039/B315732F.

[50] Shankar SS, Ahmad A, Pasricha R, Sastry M. Bioreduction of chloroaurate ions by geranium leaves and its endophytic fungus yields gold nanoparticles of different shapes. J Mater Chem. 2003;13:1822-6. doi: 10.1039/B303808B.

[51] Sivaraman SK, Elango I, Kumar S, Santhanam V. A green protocol for room temperature synthesis of silver nanoparticles in seconds. Curr Sci. 2009;97(7):1055-9. doi: 10/10/2009/00113891.

[52] Thakkar KN, Mhatre SS, Parikh RY. Biological synthesis of metallic nanoparticles. Nanomedicine. 2010;6(2):257-62. doi: 10.1016/j.nano.2009.07.002.

[53] Huang J, Li Q, Sun D, Lu Y. Biosynthesis of silver and gold nanoparticles by novels undried Cinnamomum camphora leaf. Nanotechnology. 2007;18:105-6. doi: 10.1088/09574484/18/10/105104.

[54] Narayanan KB, Sakthivel N. Green synthesis of biogenic metal nanoparticles by terrestrial and aquatic phototrophic and heterotrophic eukaryotes and biocompatible agents. Adv Colloid Interface Sci. 2011;169(2):59-79. doi: 10.1016/ j.cis.2011.08.004.
[55] Tan YN, Lee JY, Wang DI. Uncovering the design rules for peptide synthesis of metal nanoparticles. J Am Chem Soc. 2010;132(16):5677-86. doi: 10.1021/ja907454f.

[56] Park Y, Hong YN, Weyers A, Kim YS, Linhardt RJ. Polysaccharides and phytochemicals: a natural reservoir for the green synthesis of gold and silver nanoparticles. IET Nanobiotechnol. 2011;5(3):69-78. doi: 10.1049/ietnbt.2010.0033.

[57] Arunachalam KD, Annamalai SK, Hari S. One-step green synthesis and characterization of leaf extract-mediated biocompatible silver and gold nanoparticles from Memecylon umbellatum. Int J Nanomed. 2013;8:1307-15. doi: $10.2147 /$ IJN.S36670.

[58] Huang X, Wu H, Pu S, Zhang W, Liao X, Shi B. One-step roomtemperature synthesis of Au@Pd core-shell nanoparticles with tunable structure using plant tannin as reductant and stabilizer. Green Chem. 2011;13:950-7. doi: 10.1039/ c0gc00724b.

[59] Rai M, Yadav A, Gade A. Current [corrected] trends in phytosynthesis of metal nanoparticles. Crit Rev Biotechnol. 2008;28(4):277-84. doi: 10.1080/07388550802368903.

[60] Kharissova OV, Dias HVR, Kharisov BI, Jiménez-Pérez VM, Pérez BO, Flores BM. Iron-containing nanomaterials: synthesis, properties, and environmental applications. RSC Adv. 2012;2(25):9325-58. doi: 10.1039/c2ra20812a.

[61] Song JY, Kim BS. Rapid biological synthesis of silver nanoparticles using plant leaf extracts. Bioprocess Biosyst Eng. 2009;32:79-84. doi: 10.1007/s00449-0080224-6.

[62] Vinod VTP, Saravanan P, Sreedhar B, Devi DK, Sashidar RB. A facile synthesis and characterization of $\mathrm{Ag}, \mathrm{Au}$ and $\mathrm{Pt}$ nanoparticles using a natural hydrocolloid gum kondagogu (Cochlospermum gossypium). Colloids Surf B Biointerfaces. 2011;83(2):291-8. doi: 10.1016/j.colsurfb.2010.11.035.

[63] Shaojun G, Erkang W. Review: noble metal nanomaterials: controllable synthesis and application in fuel cells and analytical sensors. Nano Today. 2011;6:240-64. doi: 10.1016/j.nantod.2011.04.007.

[64] Tapan AS, Andrey LR. Nonspherical noble metal nanoparticles: colloid-chemical synthesis and morphology control. Adv Mater. 2010;22(16):1781-804. doi: 10.1002/ adma.200901271.

[65] Yugeng W, Yunqi L, Chong-an D, Ying W, Sun X, Yunlong G, et al. Improvements in stability and performance of $N, N^{\prime}$ dialkyl perylene diimide-based n-type thin-film transistors. Prog Chem. 2009;21(16):1631-5. doi: 10.1002/ adma.200802934.

[66] Oijerholm J, Forsberg S, Hermansson HP, Ullberg M. Relation between the SHE and the internal $\mathrm{Ag} / \mathrm{AgCl}$ reference electrode at high temperatures. J Electrochem Soc. 2009;156(3):56-61. doi: 10.1149/1.3056125.

[67] Lim B, Jiang M, Camargo PHC, Cho EC, Tao J, Lu X, et al. Pd-Pt bimetallic nanodendrites with high activity for oxygen reduction. Science. 2009;324(5932):1302-5. doi: 10.1126/ science.1170377.

[68] Schrinner M, Ballauff M, Talmon Y, Kauffmann Y, Thun J, Moeller M, et al. Single nanocrystals of platinum prepared by partial dissolution of Au-Pt nanoalloys. Science. 2009;323(5914):617-20. doi: 10.1126/science.1166703. 
[69] Siavash I. Green synthesis of metal nanoparticles using plants. Green Chem. 2011;13:2638-50. doi: 10.1039/ C1GC15386B.

[70] Jurate V, Rajender SV. Green synthesis of metal nanoparticles: biodegradable polymers and enzymes in stabilization and surface functionalization. Chem Sci. 2011;2:837-46. doi: $10.1039 / \operatorname{CoSC00338G}$

[71] Mallikarjuna NN, Rajender SV. Green synthesis of silver and palladium nanoparticles at room temperature using coffee and tea extract. Green Chem. 2008;10:859-62. doi: 10.1039/ B804703K.

[72] Baruwati B, Varma SV. High value products from waste: grape pomace extract-a three-in-one package for the synthesis of metal nanoparticles. Chem Sus Chem. 2009;2:1041-5. doi: 10.1002/cssc.200900220.

[73] Mahmoud N, Reza A, Zahra I, Sajadi SM. Biosynthesis and characterization of $\mathrm{Ag} / \mathrm{MgO}$ nanocomposite and its catalytic performance in the rapid treatment of environmental contaminants (/paper Redirect/5863973). Ceram Int. 2020;46(2):2093-101. doi: 10.2016/j.ceramint.2019.09.191.

[74] Radu CF, Alina 0, Sorin MA, Irina F. Review: phytonanocatalysts: green synthesis, characterization, and applications. Molecules. 2019;24(3418):1-35. doi: 10.3390/ molecules24193418.

[75] Zahra V, Omid T, Ali N. New insights into mechanistic aspects and structure of polycrystalline $\mathrm{Cu} / \mathrm{Cr} / \mathrm{Ni}$ metal oxide nanoclusters synthesized using Eryngium campestre and Froriepia subpinnata. Korean Inst Chem Eng. 2019;36(3):489-99. doi: 10.1007/s11814-018-0216-4.

[76] Zahra V, Ali N, Omid T. Plant-mediated $\mathrm{Cu} / \mathrm{Cr} / \mathrm{Ni}$ nanoparticle formation strategy simultaneously separation of the mixed ions from aqueous solution. Taiwan Inst Chem Eng. 2019;96:148-59. doi: 10.1016/j.jtice.2018.10.020.

[77] Zahra V, Ali N, Omid T. Rapid biosynthesis of novel $\mathrm{Cu} / \mathrm{Cr} / \mathrm{Ni}$ trimetallic oxide nanoparticles with antimicrobial activity. J Environ Chem Eng. 2018;6(2):1898-911. doi: 10.1016/ j.jece.2018.02.038.

[78] Michael CM, Laura KB-S, Mallikarjuna NN, Samantha K, Saber MH, Rajender SV. Synthesis, characterization and biocompatibility of "green" synthesized silver nanoparticles using tea polyphenols. Nanoscale. 2010;2:763-70. doi: $10.1039 /$ CONR00046A.

[79] Malikarjuna NN, George H, John C, Rajender SV. Green synthesis of $\mathrm{Au}$ nanostructures at room temperature using biodegradable plant surfactants. Cryst Growth Des. 2009;9(11):4979-83. doi: 10.1021/cg9007685.

[80] Castro L, Blázquez ML, González F, Muñoz JA, Ballester A. Gold, silver and platinum nanoparticles biosynthesized using orange peel extract. Chem Eng J. 2013;825:556-9. doi: 10.4028/www.scientific.net/AMR.825.556.

[81] Castro L, Blázquez ML, Muñoz JA, González F, GarciaBalboa C, Ballester A. Biosynthesis of gold nanowires using sugar beel pulp. Process Biochem. 2011;46(5):1076-82. doi: 10.1016/j.procbio.2011.01.025.

[82] Jiahui K, Rajender SV. Beet juice utilization: expeditious green synthesis of noble metal nanoparticles $(\mathrm{Ag}, \mathrm{Au}, \mathrm{Pt}$, and Pd) using microwaves. RSC Adv. 2012;2:10283-90. doi: $10.1039 /$ c2ra21908e.

[83] Bar H, Bhui DK, Sahoo GP, Sarkar P, De SP, Mirsa A. Green synthesis of silver nanoparticles using latex of
Jatrophacurcus. Colloids Surf A, Physiochemal Eng Asp. 2009;339:134-9. doi: 10.1016/j.colsurfa.2009.02.008.

[84] Smitha SL, Philip D, Gopchandran KG. Green synthesis of gold nanoparticles using Cinnamomum zeylanicum leaf broth. Spectrochim Acta A, Mol Biomol Spectrosc. 2009;74(3):735-9. doi: 10.1016/j.saa.2009.08.007.

[85] Philip D. Rapid green synthesis of spherical gold nanoõparticles using mangifera indica leaf. Spectrochim Acta Mol Biomol. 2010;77(4):807-10. doi: 10.1016/ j.saa.2010.08.008.

[86] Chandran SP, Chaudhary M, Pasricha R, Ahmad A, Sastry M. Synthesis of gold nanotriangles and silver nanoparticles using Aloe vera plant extract. Biotechnol Prog. 2006;22(2):577-83. doi: 10.1021/bp0501423.

[87] Veeraputhiran V. Bio-catalytic synthesis of silver nanoparticles. Int J Chem Tech Res. 2013;5(5):2555-62. CODEN (USA): IJCRGG, ISSN: 0974-4290.

[88] Pallela PNVK, Ummey S, Ruddaraju LK, Pammi SVN, Yoon SG. Ultra small monodispersed green synthesized silver nanoparticles using aqueous extract of sida cordifolia plant and investigation of antibacterial activity. Micro Pathog. 2018;124:63-69. doi: 10.1016/j.micpath.2018.08.026.

[89] Mariappan A, Saswata B, Atul SD. Low temperature synthesis and characterization of single phase multi-component fluorite oxide nanoparticle sols. RSC Adv. 2019;9:26825-30. doi: $10.1039 /$ c9ra04636d.

[90] Sravani K, Lakshmi P, Swetha MK, Jhansi RS. Diospyros assimilis root extract assisted biosynthesised silver nanoparticles and their evaluation of antimicrobial activity. IET Nanotechnol. 2017;12(2):133-7. doi: org/10.1049/ietnbt.2017.0042.

[91] Lakshmi KR, Pammi SVN, Pallela PNVK, Veerabhadra SP, Kolapalli, Venkata RM. Antibiotic potentiation and anti-cancer competence through bio-mediated ZNO nanoparticles. Mater Sci Engineering: C. 2019;103:109756. doi: 10.1016/j.msec.2019.109756.

[92] Lakshmi KR, Panduranga NVKP, Pammi SVN, Veerabhadra SP, Venkata RMK. Synergetic antibacterial and anticarcinogenic effects of annona squamosa leaf extract mediated silver nanoparticles. Mater Sci Semiconductor Process. 2019;100:301-9. doi: 10.1016/j.mssp.2019.05.007.

[93] Panduranga NVKP, Shameem U, Lakshmi KR, Pratap K, Sharmila K, Pammi SVN. Antibacterial activity assessment and characterization of green synthesized $\mathrm{CuO}$ nano rods using Asparagus racemosus roots extract. SN Applied Science. 2019;1:421. doi: 10.1007/s42452-019-0449-9.

[94] Vijay Kumar PNN, Kalyani RL, Sarath CV, Pratap K, Shameem U, Pammi SVN. Biogenic synthesis of stable silver nanoparticles via Asparagus racemosus root extract and their antibacterial efficacy towards human and fish bacterial pathogens. Mater Res Express. 2019;6(10):1-22. doi: 10.1088/2053-1591/ab3ce9.

[95] Zenk MH. Heavy metal detoxification in higher plantsa review. Gene. 1996;179(1):21-30. doi: 10.1016/S03781119(96)00422-2.

[96] Cobbett CS. Phytochelatin biosynthesis and function in heavy-metal detoxification. Curr Opin Plant Biol. 2000;3(3):211-6. doi: 10.1016/S1369-5266(00)80067-9.

[97] Yadav SK. Heavy metals toxicity in plants: an overview on the role of glutathione and phytochelatins in heavy metal stress 
tolerance of plants. S Afr J Bot. 2010;76(2):167-79. doi: $10.1016 /$ j.sajb.2009.10.007.

[98] Rascio N, Navari-Izzo F. Heavy metal hyper accumulating plants: how and why do they do it? And what makes them so interesting? J Plant Sci. 2011;180(2):169-81. doi: 10.1016/ j.plantsci.2010.08.016.

[99] Malik P, Shankar R, Malik V, Sharma N, Mukherjee TK. Green chemistry based benign routes for nanoparticle synthesis. J Nanopart. 2014;3:1-14. doi: 10.1155/2014/302429.

[100] Prathna TC, Mathew L, Chandrasekaran N, Raichur AM, Mukherjee A. Biomimetic synthesis of nanoparticles: science, technology and applicability. In: Mukherjee A, editor. Biomimetics Learning from Nature, Nature Publishing Group. Intech. Open Access; 2010, ch. 1. ISBN: 978-953-307025-4; eBook (PDF) ISBN: 978-953-51-4555-4. doi: $10.5772 / 198$.

[101] Mittal AK, Chisti Y, Banerjee UC. Synthesis of metallic nanoparticles using plant extracts. Biotechnol Adv. 2013;31(2):346-56. doi: 10.1016/j.biotechadv.2013.01.003.

[102] Jha AK, Prasad K, Kumar V, Prasad K. Biosynthesis of silver nanoparticles using Eclipta leaf. Biotechnol Prog. 2009;25(5):1476-9. doi: 10.1002/btpr.233.

[103] Thamima M, Karuppuchamy S. Biosynthesis of titanium dioxide and zinc oxide nanoparticles from natural sources: a review. Adv Sci Eng Med. 2015;7(1):18-25. doi: 10.1166/ asem.2015.1648.

[104] Benelli G. Plant-borne ovicides in the fight against mosquito vectors of medical and veterinary importance: a systematic review. Parasitol Res. 2015;114(9):3201-12. doi: 10.1007/ s00436-015-4656-z.

[105] Mukunthan KS, Balaji S. Cashew apple juice (Anacardium occidentale L.) speeds up the synthesis of silver nanoparticles. Int J Green Nanotechnol. 2012;4(2):71-79. doi: 10.1080/19430892.2012.676900.

[106] Li X, Xu H, Chen ZS, Chen G. Review article: biosynthesis of nanoparticles by microorganisms and their applications. J Nanomater. 2011;1-16. doi: 10.1155/2011/270974.

[107] Richardson A, Chan BC, Crouch RD, Janiec A. Synthesis of silver nanoparticles: an under -graduate laboratory using green approach. Chem Educ. 2006;11:331-3. doi: 10.3390/ ijerph10105221.

[108] Li S, Shen Y, Xie A, Yu X, Qiu L, Zhang L, et al. Green synthesis of silver nanoparticles using Capsicum annuum L. extract. Green Chem. 2007;9(8):852-8. doi: 10.1039/ B615357G.

[109] Huang J, Li Q, Sun D, Lu Y, Su Y, Yang X, et al. Biosynthesis of silver and gold nanoparticles by novel sundried Cinnamomum camphoraleaf. Nanotechnology. 2007;18(10):105104-15. doi: 10.1088/0957-4484/18/10/105104

[110] Kesharwani J, Yoon KY, Hwang J, Rai M. Phytofabrication of silver nanoparticles by leaf extract of datura metal: hypothetical mechanism involved in synthesis. J Bionanosci. 2009;3(1):39-44. doi: 10.1166/jbns.2009.1008.

[111] Iravani S. Green synthesis of metal nanoparticles using plants. Green Chem. 2011;13(10):2638-50. doi: 10.1039/ C1GC15386B.

[112] Mukherjee S, Sushma V, Patra S, Barui AK, Bhadra MP, Sreedhar B, et al. Green chemistry approach for the synthesis and stabilization of biocompatible gold nanoparticles and their potential applications in cancer therapy.
Nanotechnology. 2012;23(45):455103. doi: 10.1088/09574484/23/45/455103.

[113] Newman JDS, Blanchard GJ. Formation of gold nanoparticles using amine reducing agents. Langmuir. 2006;22(13):5882-7. doi: 10.1021/la060045z.

[114] Makarov VV, Love AJ, Sinitsyna OV, Shaw J, Yaminsky IV, Kalinina NO, et al. A genetically modified tobacco mosaic virus that can produce gold nanoparticles from a metal salt precursor. Front Plant Sci. 2015;6:1-10. doi: 10/3389/ fpls.2015.00984.

[115] Si S, Mandal TK. Tryptophan-based peptides to synthesize gold and silver nanoparticles: a mechanistic and kinetic study. Chem Eur J. 2007;13(11):3160-8. doi: 10.1002/ chem. 200601492.

[116] Akhtar MS, Panwar J, Yun Y-S. Biogenic synthesis of metallic nanoparticles by plant extracts. ACS Sustain Chem Eng. 2013;1(6):591-602. doi: 10/1021/sc300118u.

[117] Pomogailo AD, Kestelman VN, editors. Metallopolymer Nanocomposites. Berlin Heidelberg New York: Springer; 2005.

[118] Feng H, Dongye Z, Juncheng L, Christopher BR. Stabilization of Fe-Pd nanoparticles with sodium carboxymethyl cellulose for enhanced transport and dechlorination of trichloroethylene in soil and ground waste. Ind Eng Chem Res. 2007;46(1):29-34. doi: 10.1021/ie0610896.

[119] Jurate V, Rajender SV. Green synthesis of metal nanoparticles: biodegradable polymers and enzymes in stabilization and surface functionalization. Chem Sci. 2011;2:837-46. doi: 10.1039/COSC00338G.

[120] Yang T, Li Z, Wang L, Guo C, Sun Y. Synthesis, characterization, and self-assembly of protein lysozyme monolayerstabilized gold nanoparticles. Langmuir. 2007;23(21):10533-8. doi: 10.1021/la701649z.

[121] Babita B, Rajender SV. High value products from waste: grape pomace extract-a three-in-one package for the synthesis of metal nanoparticles. ChemSusChem. 2009;2:1041-4. doi: 10.1002/cssc.200900220.

[122] Vivek P, Rajender SV. Green chemistry by nano-catalysis. Green Chem. 2010;12:743-54. doi: 10.1039/B921171C.

[123] Rangnekar A, Sarma TK, Singh AK, Deka J, Ramesh A, Chattopadhyay A. Retention of enzymatic activity of alphaamylase in the reductive synthesis of gold nanoparticles. Langmuir. 2007;23(10):5700-6. doi: 10.1021/la062749e.

[124] Raed A-R, Howard A, Dashan W, Michael LP. Metal supported on dendronized magnetic nanoparticles: highly selective hydroformylation catalysts. J Am Chem Soc. 2006;128(15):5279-82. doi: 10.1021/ja060140u.

[125] Baruwati B, Polshettiwar V, Varma RS. Magnetically recoverable supported ruthenium catalyst for hydrogenation of alkynes and transfer hydrogenation of carbonyl compounds. Tetrahedron Lett. 2009;50(11):1215-8. doi: 10.1016/ j.tetlet.2009.01.014.

[126] Polshettiwar V, Babita B, Varma RS. Nanoparticle-supported and magnetically recoverable nickel catalyst: a robust and economic hydrogenation and transfer hydrogenation protocol. Org Biomol Chem. 2009;7:37-40. doi: 10.1039/B815058C.

[127] Polshettiwar V, Rajender SV. Nanoparticle-supported and magnetically recoverable ruthenium hydroxide catalyst: efficient hydration of nitriles to amides in aqueous medium. Chem-Eur J. 2009;15:1582-6. doi: 10.1002/ chem. 200802264 . 
[128] Suprakas SR, Mosto B. Biodegradable polymers and their layered silicate nanocomposites. Green 21st Century Mater World. 2005;50(8):962-1079.

[129] Rozenberg BA, Tenne R. Polymer-assisted fabrication of nanoparticles and nanocomposites. Prog Polym Sci. 2008;33(1):40-112. doi: 10.1016/j.progpolymsci.2007. 07.004 .

[130] Qiu H, Rieger J, Gilbert B, Jérôme R, Jérôme C. PLA-coated gold nanoparticles for the labeling of PLA biocarriers. Chem Mater. 2004;16(5):850-6. doi: 10.1021/cm034519g.

[131] Christodoulakis KE, Palioura D, Anastasiadis SH, Vamvakaki M. Metal nano-crystals embedded with polymeric Nanostructures: effect of polymer-metal compound interactions. Top Catal. 2009;52(4):394-411. doi: 10.1007/ s11244-008-9172-2.

[132] Ragheb RT, Riffle JS. Synthesis and characterization of poly (lactide-b-siloxane-b-lactide) copolymers as magnetite nanoparticle dispersants. Polymer. 2008;49(5):5397-404. doi: 10.1016/j.polymer.2008.09.020.

[133] Morones JR, Frey W. Environmentally sensitive silver nanoparticles of controlled size synthesized with PNIPAM as a nucleating and capping agent. Langmuir. 2007;23:8180-6. doi: $10.1021 /$ la7008336.

[134] Garcia-Serrano J, Pal U, Herrera AM, Salas P, AngelesChavez C. One-step "Green" synthesis and stabilization of $\mathrm{Au}$ and $\mathrm{Ag}$ nanoparticles using ionic polymers. Chem Mater. 2008;20(16):5146-53. doi: 10.1021/cm703201d.

[135] Nadagouda MN, Varma RS. Synthesis of thermally stable carboxymethyl cellulose/metal biodegradable nanocomposites for potential biological applications. Biomacromolecules. 2007;8:2762-7. doi: 10.1021/ bm700446p.

[136] Nadagouda MN, Varma RS. Microwave-assisted shape controlled bulk synthesis of noble nanocrystals and their catalytic properties. Cryst Growth Des. 2007;7:686-690. doi: 10.1021/cg060506e.

[137] Mallikarjuna NN, Rajender SV. Green and controlled synthesis of gold and platinum nanomaterials using vitamin B2: density-assisted self-assembly of nanospheres, wires and rods. J Am Chem Soc. 2006;8:516-8. doi: 10.1039/ B601271).

[138] Mallikarjuna NN, Rajender SV. A greener synthesis of core (Fe, $\mathrm{Cu}$ )-Shell ( $\mathrm{Au}, \mathrm{Pt}, \mathrm{Pd}$, and $\mathrm{Ag}$ ) nanocrystals using aqueous vitamin C. Cryst Growth Des. 2007;7(12):2582-7. doi: 10.1021/cg070554e.

[139] Raj NK, Sripal RM, Chaluvadi MR, Krishna DR. Bioflavonoids classification, pharmacological, biochemical effects and therapeutic potential. Indian J Pharmacol. 2001;33(1):2-16. ISSN: 0253-7613, http://bmj.com/cgi/content/full/322/ $7282 / 329$.

[140] Ahmad N, Sharma S, Alam MK, Singh VN, Shamsi SF, Mehta BR, et al. Rapid synthesis of silver nanoparticles using dried medicinal plant of basil. Colloids Surf B. 2010;81(1):81-6. doi: 10.1016/j.colsurfb.2010.06.029.

[141] Zheng B, Kong T, Jing X, Wubah TO, Li X, Sun D, et al. Plantmediated synthesis of platinum nanoparticles and its bioreductive mechanism. J Colloid Interface Sci. 2013;396:138-45. doi: 10.1016/j.jcis.2013.01.021.

[142] Senthilkumar SR, Sivakumar T. Green tea (Camellia sinensis) mediated synthesis of zinc oxide ( $\mathrm{ZnO}$ ) nanoparticles and studies on their antimicrobial activities. Int J Pharm Sci. 2014;6(6):461-5, ISSN:0975-1491.

[143] Sharbidre AA, Kasote DM. Synthesis of silver nanoparticles using flaxseed hydroalcoholic extract and its antimicrobial activity. Curr Biotechnol. 2013;2(2):162-6. doi: 10.2174/ 22115501113029990007.

[144] Shabnam N, Saradhi PP, Sharmila P. Phenolics impart $\mathrm{Au}^{3+}$ stress tolerance to Cowpea by generating nanoparticles. PLoS One. 2014;9(1):85241-7. doi: 10.1371/ journal.pone.0085242.

[145] Ahmad N, Sharma S. Green synthesis of silver nanoparticles using extracts of Ananas comosus. Green Sustain Chem. 2012;2(4):141-7. doi: 10/4236/gsc.2012.24020.

[146] Rai M, Posten C, editor. Green Biosynthesis of Nanoparticles: Mechanisms and Applications. Oxford Shire: CABI; 2013. p. 248. ISBN: 9781780642239.

[147] Laghari AQ, Memon S, Nelofar A, Laghari AH. Structurally diverse alkaloids from Tecomella undulata G. Don flowers. J King Saud Univ, Sci. 2014;26(4):300-4. doi: 10.1016/ j.jksus.2014.02.005.

[148] Gnanasangeetha D, Thambavani SD. Facile and eco-friendly method for the synthesis of zinc oxide nanoparticles using azadirachta and emblica. Int J Pharm Sci Res. 2014;5(7):2866-73. E-ISSN: 0975-8232; P-ISSN: 2320-5148.

[149] Raminelli AC, Romero V, Semreen MH, Leonardi GR. Nanotechnological advances for cutaneous release of tretinoin: an approach to minimize side effects and improve therapeutic efficacy. Curr Med Chem. 2018;25(31):3703-18. doi: 10.1016/j.nano.2019.102117.

[150] Chandran K, Song S, Yun S-I. Effect of size and shape controlled biogenic synthesis of gold nanoparticles and their mode of interactions against food borne bacterial pathogens. Arab J Chem. 2014, in press. doi: 10.1016/ j.arabjc.2014.11.041.

[151] Mishra A, Kumar S, Pandey AK. Scientific validation of the medicinal efficacy of Tinospora cordifolia. Sci World J. 2013;2013:1-8. doi: 10.1155/2013/292934.

[152] Halliwell B, Gutteridge JMC. Free Radicals in Biology and Medicine. 5th ed. Oxford: Oxford University Press; 2015. ISBN-13: 9780198717478. doi: 10.1093/acprof:oso/ 9780198717478.001.0001.

[153] Zhu W, Jia Q, Wang Y, Zhang Y, Xia M. The anthocyanin cyanidin-3-0- $\beta$-glucoside, a flavonoid, increases hepatic glutathione synthesis and protects hepatocytes against reactive oxygen species during hyperglycemia: Involvement of a cAMP-PKA-dependent signaling pathway. Free Radic Biol Med. 2012;52(2):314-27. doi: 10.1016/ j.freeradbiomed.2011.10.483.

[154] Mishra A, Sharma AK, Kumar S, Saxena AK, Pandey AK. Bauhinia variegata leaf extracts exhibit considerable antibacterial, antioxidant, and anticancer activities. BioMed Res Int. 2013;2013:1-10. doi: 10.1155/2013/915436.

[155] Boutin C, Freemark C. Review: impacts of agricultural herbicide use on terrestrial wildlife in temperate landscapes: A review with special reference to North America. Agri Ecosyst Env. 1995;2-3:67-91. doi: 10.1016/0167-8809(94)00534-L.

[156] Gerdin B, Svensjö E. Inhibitory effect of the flavonoid O-(beta-hydroxyethyl)-rutoside on increased microvascular permeability induced by various agents in rat skin. Int J Microcirc: Clin Exp. 1983;2(1):39-46. PMID: 6088413. 
[157] Cushnie TPT, Lamb AJ. Antimicrobial activity of flavonoids. Int J Antimicrob Agents. 2005;26(5):343-56. doi: 10.1016/ j.ijantimicaq.2005.09.002.

[158] Li BQ, Fu T, Dongyan Y, Mikovits JA, Ruscetti FW, Wang JM. Flavonoid baicalin inhibits HIV-1 infection at the level of viral entry. Biochem Biophys Res Commun. 2000;276(2):534-8. doi: $10.1006 /$ bbrc.2000.3485.

[159] Critchfield JW, Butera ST, Folks TM. Inhibition of HIV activation in latently infected cells by flavonoid compounds. AIDS Res Hum Retroviruses. 1996;12(1):39-46. doi: 10.1089/ aid.1996.12.39.

[160] Jaiswal PV, ljeri VS, Srivastava AK. Voltammetric behavior of certain vitamins and their determination in surfactant media. Anal Sci. 2001;17:741-4. doi: 10.14891/ analscisp.17icas.0.i741.0.

[161] Kocot J, Luchowska-Kocot D, Kiełczykowska M, Musik I, Kurzepa J. Does vitamin $C$ influence neurodegenerative diseases and psychiatric disorders? Nutrients. 2017;9(7):659. doi: 10.3390/nu9070659.

[162] Sunil K, Singh S, Verma R. Anticancer potential of dietary vitamin D and ascorbic acid: a review. Crit Rev Food Sci Nutr. 2017;57(12):2623-35. doi: 10.1080/10408398.2015. 1064086.

[163] Stamford NP. Stability, transdermal penetration, and cutaneous effects of ascorbic acid and its derivatives. J Cosmet Dermatol. 2012;11:310-7. doi: 10.1080/10408398.2015. 1064086.

[164] Khan A, Rashid A, Younas R, Chong R. A chemical reduction approach to the synthesis of copper nanoparticles. Int Nano Lett. 2016;6:21-26. doi: 10.1007/s40089-015-0163-6.

[165] Sun K, Qiu Q, Liu J, Miao Y. Preparation and characterization of gold nanoparticles using ascorbic acid as reducing agent in reverse micelles. J Mater Sci. 2009;44(3):754-8. doi: 10.1007/s10853-008-3162-4.

[166] D'souza SL, Patia RK, Kailasa SK. Ascorbic acid functionalized gold nanoparticles as a probe for colorimetric and visual read-out determination of dichlorvos in environmental samples. Anal Methods. 2014;6(22):9007-14. doi: 10.1039/ C4AY01004C.

[167] Dumay 0, Costa J, Desjobert J-M, Pergent G. Variations in the concentration of phenolic compounds in the seagrass posidonia oceanica under conditions of competition. Phytochemistry. 2004;65(24):3211-20. doi: 10.1016/ j.phytochem.2004.09.003.

[168] Lam TB, Kadoya K, liyama K. Bonding of hydroxycinnamic acids tolignin: ferulic and $p$-coumaric acids are predominantly linked at the benzyl position of lignin, not the B-position, in grass cell walls. Phytochemistry. 2001;57(6):987-92. doi: 10.1016/s0031-9422(01)00052-8.

[169] Silke K, Karl H. Glucosides and glucose esters of hydroxybenzoic acids in plants. Phytochemistry. 1988;27(7):2177-80. doi: 10.1016/0031-9422(88)80121-3.

[170] Balasundram N, Sundram K, Samman S. Phenolic compounds in plants and agri-industrial by-products: antioxidant activity, occurrence, and potential uses. Food Chem. 2006;99(1):191-203. doi: 10.1016/j.foodchem.2005.07.042.

[171] Natella F, Nardini M, Di Felice M, Scaccini C. Benzoic and cinnamic acid derivatives as antioxidants: structure-activity relation. J Agric Food Chem. 1999;47(4):1453-9. doi: 10.1021/jf980737w.
[172] Kassim M, Achoui M, Mustafa MR, Mohd MA, Yusoff KM. Ellagic acid, phenolic acids, and flavonoids in Malaysian honey extracts demonstrate in vitro anti-inflammatory activity. Nutr Res. 2010;30(9):650-9. doi: 10.1016/ j.nutres.2010.08.008.

[173] Wang P, NI Y-N. Silver nanoparticles preparation using antioxidant propyl gallate and its analytical application. Chem J Chin Univ-Chin. 2013;34(4):837-40. doi: org/ 10.1016/S0031-9422(01)00052-8.

[174] Hui YW, Yuan FL, Cheng ZH. Detection of ferulic acid based on the plasmon resonance light scattering of silver nanoparticles. Talanta. 2007;72(5):1698-703. doi: 10.1016/ j.talanta.2007.02.028.

[175] Hyun-soek K, Yu SS, Kyeounghak K, Jeong WH, Youmie P, Seonho $C$. Concentration effect of reducing agents on green synthesis of gold nanoparticles: size, morphology, and growth mechanism. Nanoscale Res Lett. 2016;11(1):230-9. doi: 10.1186/s11671-016-1393-x.

[176] Scampicchio M, Wang J, Blasco AJ, Sanchez AA, Mannino S, Escarpa A. Nanoparticle-based assays of antioxidant activity. Anal Chem. 2006;78(6):2060-3. doi: 10.1021/ ac052007a.

[177] Li W, Gang W, Lanlan S, Zhiguo L. Self-assembly of cinnamic acid-capped gold nanoparticles. Nanotechnology. 2006;17(12):2907-12. doi: 10.1088/0957-4484/17/12/014.

[178] Schliebe C, Jiang K, Schulze S, Hietschold M, Cai WB, Lang H. A convenient light initiated synthesis of silver and gold nanoparticles using a single source precursor. Chem Commun. 2013;49(38):3991-3. doi: 10.1088/0957-4484/17/ $12 / 014$.

[179] Nilsson L, Löf D, Bergenståhl Br. Phenolic acid nanoparticle formation in iron-containing aqueous solutions. J Agric Food Chem. 2008;56(23):11453-7. doi: 10.1021/ jf8025925.

[180] Elnaz S, Seyed SA, Sharmin K, Roksana T. Curcumin coated gold nanoparticles: synthesis, characterization, cytotoxicity, antioxidant activity and its comparison with citrate coated gold nanoparticles. Nanomed J. 2017;4(2):115-25. doi: 10.22038/nmj.2017.21506.1227.

[181] Palanivel S, Feng LG, Qiuqiang Z, Palvannan T. Flavonoids mediated 'green' nanomaterials: a novel nanomedicine system to treat various diseases-current trends and future perspective. Mater Lett. 2018;210:26-30. doi: 10.1016/ j.matlet.2017.08.078.

[182] Anand BG, Dubey K, Shekhawat DS, Kar K. Capsaicin-coated silver nanoparticles inhibit amyloid fibril formation of serum albumin. Biochemistry. 2016;55(24):3345-8. doi: 10.1021/ acs.biochem.6b00418.

[183] Ye Q, Feng Z, Weimin L. Bioinspired catecholic chemistry for surface modification. Chem Soc Rev. 2011;40(7):4244-58. doi: 10.1039/C1CS15026).

[184] Ata MS, Liu Y, Zhitomirsky I. A review of new methods of surface chemical modification, dispersion and electrophoretic deposition of metal oxide particles. RSC Adv. 2014;4(43):22716-32. doi: 10.1039/C4RA02218A.

[185] Hanaka K, Riho H, Issey O, Takao H, Katano H, Shu T. Nanoparticle-assisted laser desorption/ionization using sinapic acid-modified iron oxide nanoparticles for mass spectrometry analysis. Analyst. 2015;140(24):8134-7. doi: 10.1039/C5AN02081F. 
[186] Lee J, Choi KH, Min J, Kim HJ, Jee JP, Park BJ. Functionalized $\mathrm{ZnO}$ nanoparticles with gallic acid for antioxidant and antibacterial activity against methicillin resistant S. Aureus. Nanomaterials. 2017;7(11):365. doi: 10.3390/nano7110365.

[187] Mihaiescu DE, Buteică AS, Neamţu J, Istrati D, Mîndrilã I. $\mathrm{Fe}_{3} \mathrm{O}_{4}$ /salicylic acid nanoparticles behavior on chick cam vasculature. J Nanopart Res. 2013;15(8):1857. doi: 10.1007/ s11051-013-1857-1.

[188] Anand BG, Shekhawat DS, Dubey K, Kar K. Uniform, polycrystalline, and thermostable piperine-coated gold nanoparticles to target insulin fibril assembly. ACS Biomater Sci Eng. 2017;3(6):1136-45. doi: 10.1021/ acsbiomaterials.7b00030.

[189] Wang L, Wei G, Sun L, Li Z. Self-assembly of cinnamic acidcapped gold nanoparticles. Nanotechnology. 2006;17(12):2907. doi: 10.1088/0957-4484/17/12/014.

[190] Yu SS, Eun-Young A, Youmine P, Jisu P, Tae YK, Jee EH, et al. Catalytic reduction of 4-nitrophenol with gold nanoparticles synthesized by caffeic acid. Nanoscale Res Lett. 2017;12(1):7. doi: 10.1186/s11671-016-1776-z.

[191] Mittal AK, Kumar S, Banerjee UC. Quercetin and gallic acid mediated synthesis of bimetallic (silver and selenium) nanoparticles and their antitumor and antimicrobial potential. J Colloid Interface Sci. 2014;431:194-9. doi: 10.1016/j.jcis.2014.06.030.

[192] Jiang X, Yu A. One-step approach for the synthesis and selfassembly of silver nanoparticles. J Nanosci Nanotechnol. 2010;10(11):7643-7. doi: 10.1166/jnn.2010.2763.

[193] Mîndrilă I, Buteică SA, Mihaiescu DE, Badea G, Fudulu A, Mărgăritescu DN. $\mathrm{Fe}_{3} \mathrm{O}_{4}$ /salicylic acid nanoparticles versatility in magnetic mediated vascular nanoblockage. J Nanopart Res. 2016;18(1):10. doi: 10.1007/s11051-0153318-5.

[194] Seyed MA, Abolfazl A. Review article: metal nanoparticles synthesis through natural phenolic acids. IET Nanobiotechnology. 2019;13(2):1-9. doi: 10.1049/ietnbt.2018.5386.

[195] Nadagouda MN, Speth T, Varma RS. Microwave-assisted green synthesis of silver nanostructures. Acc Chem Res. 2011;44:469-78. doi: 10.1021/ar1001457.

[196] Nadagouda MN, Varma RS. Preparation of novel metallic and bimetallic cross-linked poly(vinyl alcohol) nanocomposites under microwave irradiation. Macromol Rapid Commun. 2007;28:465-72. doi: 10.1002/marc.200600735.

[197] Nadagouda MN, Varma RS. Microwave-assisted synthesis of crosslinked poly(vinyl alcohol) nanocomposites comprising single-walled carbon nanotubes, multi-walled carbon nanotubes, and Buckminsterfullerene. Macromol Rapid Commun. 2007;28:842-7. doi: 10.1002/marc.200600878.

[198] Nadagouda MN, Varma RS. Noble metal decoration and alignment of carbon nanotubes in carboxymethyl cellulose. Macromol Rapid Commun. 2008;29:155-9. doi: 10.1002/ marc. 200700616.

[199] Nadagouda MN, Varma RS. Microwave-assisted shape controlled bulk synthesis of $\mathrm{Ag}$ and fenanorodsin poly (ethyleneglycol) solutions. Cryst Growth Des. 2008;8:291-5. doi: $10.1021 / \operatorname{cg} 070473 i$.

[200] Baruwati B, Varma RS. Synthesis of monodispersed tantalum (v) oxide nanospheres by an ethylene glycol mediated route. Cryst Growth Des. 2010;10:3424-8. doi: 10.1021/cg100123q.
[201] Nadagouda MN, Varma RS. Dextrose-templated microwave assisted combustion synthesis of spongy metal oxides. Smart Mater Struct. 2006;15:1260. doi: 10.1088/0964-1726/ 15/5/015.

[202] Nadagouda MN, Varma RS. Room temperature bulk synthesis of silver nanocables wrapped with polypyrrole. Macromol Rapid Commun. 2007;28:2106-11. doi: 10.1002/ marc. 200700495.

[203] Baruwati B, Nadagouda MN, Varma RS. Bulk synthesis of monodisperse ferrite nanoparticles at water-organic interfaces under conventional and microwave hydrothermal treatment and their surface functionalization. J Phys Chem C. 2008;112:18399-404. doi: 10.1021/jp807245g.

[204] Polshettiwar V, Nadagouda MN, Varma RS. The synthesis and applications of a micro-pine-structured nanocatalyst. Chem Commun. 2008;6318-20. doi: 10.1039/ B814715A.

[205] Mohammadinejad R, Karimi S, Iravani S, Varma RS. Plantderived nanostructures: types and applications. Green Chem. 2016;18:20-52. doi: 10.1039/C5GC01403D.

[206] Ma JK, Chikwamba R, Sparrow P, Fischer R, Mahoney R, Twyman RM. Plant-derived pharmaceuticals - the road forward. Trends Plant Sci. 2005;10:580-5. doi: 10.1016/ j.tplants.2005.10.009.

[207] Ma JKC, Drake PMW. The production of recombinant pharmaceutical proteins in plants. Christou P, Nat Rev Genet. 2003;4:794-805. doi: 10.1038/nrg1177.

[208] Schillberg S, Raven N, Fischer R, Twyman RM, Schiermeyer A. Molecular farming of pharmaceutical proteins using plant suspension cell and tissue cultures. Curr Pharm Des. 2013;19:5531-42. doi: 10.2174/1381612811319310008.

[209] Wang P, Lombi E, Zhao F-J, Kopittke PM. Nanotechnology: a new opportunity in plant sciences. Trends Plant Sci. 2016;21:699-712. doi: 10.1016/j.tplants.2016.04.005.

[210] Jia L, Zhao Y. Current evaluation of the millennium phytomedicine-ginseng( $($ ): etymology, pharmacognosy, phytochemistry, market and regulations. Curr Med Chem. 2009;16:2475-84. doi: 10.2174/092986709788682146.

[211] Aromal SA, Philip D. Green synthesis of gold nanoparticles using trigonella foenum-graecum and its size-dependent catalytic activity. Spectrochim Acta, Part A. 2012;97:1-5. doi: 10.1016/j.saa.2012.05.083.

[212] Deorukhkar A, Krishnan S, Sethi G, Aggarwal BB. Back to basics: how natural products can provide the basis for new therapeutics. Expert Opin Invest Drugs. 2007;16:1753-73. doi: $10.1517 / 13543784.16 .11 .1753$.

[213] Nishino H, Satomi Y, Tokuda H, Masuda M. Cancer control by phytochemicals. Curr Pharm Des. 2007;13:3394-9. doi: 10.2174/138161207782360519.

[214] Albrecht MA, Evans CW, Raston CL. Green chemistry and the health implications of nanoparticles. Green Chem. 2006;8:417-32. doi: 10.1039/B517131H.

[215] Siddiqui IA, Adhami VM, Bharali DJ, Hafeez BB, Asim M, Khwaja SI, et al. Introducing nanochemo prevention as a novel approach for cancer control: proof of principle with green tea polyphenol epigallocatechin-3-gallate. Cancer Res. 2009;69:1712-6. doi: 10.1158/0008-5472.CAN08-3978.

[216] Aminianfar M, Parvardeh S, Soleimani M. In vitro and in vivo assessment of silver nanoparticles against Clostridium 
botulinum type A botulinum. Curr Drug Discovery Technol. 2018;15(1):1-7. doi: 10.2174/1570163815666180403163946.

[217] Gunasekaran T, Haile T, Nigusse T, Dhanaraju MD. Nanotechnology: an effective tool for enhancing bioavailability and bioactivity of phytomedicine. Asian Pac J Trop Biomed. 2014;4:S1-S7. doi: 10.12980/APJTB.4.2014C980.

[218] Su Y, Fu Z, Zhang J, Wang W, Wang H, Wang Y, et al. Microencapsulation of Radix salvia miltiorrhiza nanoparticles by spray - drying. Powder Technol. 2008;184:114-21. doi: 10.1016/j.powtec.2007.08.014.

[219] Mata R, Bhaskaran A, Sadras SR. Green-synthesized gold nanoparticles from plumeria alba flower extract to augment catalytic degradation of organic dyes and inhibit bacterial growth. Particuology. 2016;24:78-86. doi: 10.1016/ j.partic.2014.12.014.

[220] Yu J, Xu D, Guan HN, Wang C, Huang LK. Facile one-step green synthesis of gold nanoparticles using citrus maxima aqueous extracts and its catalytic activity. Mater Lett. 2016;166:110-2. doi: 10.1016/j.matlet.2015.12.031.

[221] Nair R, Varghese SH, Nair BG, Maekawa T, Yoshida Y, Kumar DS. Nanoparticulate material delivery to plants. Plant Sci. 2010;179:154-63. doi: 10.1016/j.plantsci.2010.04.012.

[222] Bar H, Bhui DK, Sahoo GP, Sarkar P, De SP, Misra A. Green synthesis of silver nanoparticles using latex of Jatropha curcas. Colloids Surf, A. 2009;339:134-9. doi: 10.1016/ j.colsurfa.2009.02.008.

[223] Cruz D, Falé PL, Mourato A, Vaz PD, Serralheiro ML, Lino ARL. Preparation and physicochemical characterization of $\mathrm{Ag}$ nanoparticles biosynthesised by Lippia citriodora (Lemon Verbena). Colloids Surf, B. 2010;81:67-73. doi: 10.1016/ j.colsurfb.2010.06.025.

[224] Iravani S, Korbekandi H, Mirmohammadi S, Zolfaghari B. Synthesis of silver nanoparticles: chemical, physical and biological methods. Res Pharm Sci. 2014;9(6):385-406. PMID: 26339255.

[225] Raie DS, Mhatre E, Thiele M, Labena A, El-Ghannam G, Farahat LA, et al. Application of quercetin and its bioinspired nanoparticles as anti-adhesive agents against Bacillus subtilis attachment to surface. Mater Sci Eng, C. 2017;70:753-62.

[226] Dahoumane SA, Mechouet M, Wijesekera K, Filipe CD, Sicard C, Bazylinski DA, et al. Algae-mediated biosynthesis of inorganic nanomaterials as a promising route in nanobiotechnology - a review. Green Chem. 2017;19:552-87. doi: 10.1039/C6GC02346K.

[227] Voigt S. Biologische Untersuchungen über kolloidales Silber mittels einer neuen methode zum nachweis feinster metallablagerungen in den organen. Dtsch Med Wochenschr. 1914;40:483-4. doi: 10.1055/s-0029-1190235.

[228] Mohammadinejad R, Shavandi A, Raie DS, Sangeetha J, Soleimani M, Hajibehzad SS, et al. Plant molecular farming: production of metallic nanoparticles and therapeutic proteins using green factories. Green Chem. 2019;21:1845-65. doi: $10.1039 /$ C9GC00335E.

[229] Hibbard RP, Miller E. Biochemical studies on seed viability I. measurements of conductance and reduction. Plant Physiol. 1928;3(3):335-52. doi: 10.1104/pp.3.3.335.

[230] Peralta-Videa JR, Huang Y, Parsons JG, Zhao L, LopezMoreno L, Hernandez-Viezcas JA, et al. Plant-based green synthesis of metallic nanoparticles: scientific curiosity or a realistic alternative to chemical synthesis. Nanotechnol Env Eng. 2016;1:4. doi: 10.1007/s41204-016-0004-5.

[231] Patel K, Bharatiya B, Mukherjee T, Soni T, Shukla A, Suhagia B. Role of stabilizing agents in the formation of stable silver nanoparticles in aqueous solution: characterization and stability study. J Dispers Sci Technol. 2017;38:626-31. doi: 10.1080/01932691.2016.1185374.

[232] Gardea-Torresdey J, Tiemann K, Gamez G, Dokken K, Tehuacanero S, Jose-Yacaman M. Gold nanoparticles obtained by bio-precipitation from gold(III) solutions. J Nanopart Res. 1999;1:397-404. doi: 10.1023/ A:1010008915465.

[233] Gardea-Torresdey J, Parsons J, Gomez E, Peralta-Videa J, Troiani H, Santiago P, et al. Formation and growth of Auinside life alfalfa plants nanoparticle. Nano Lett. 2002;2(4):397-401.

[234] Vijayakumar S, Vaseeharan B, Malaikozhundan B, Gopi N, Ekambaram P, Pachaiappan R, et al. Therapeutic effects of gold nanoparticles synthesized using Musa paradisiaca Peel extract against multiple antibiotic resistant Enterococcus faecalis biofilms and human lung cancer cells (A549). Microb Pathog. 2017;102:173-83. doi: 10.1016/ j.micpath.2016.11.029.

[235] Netala VR, Bukke S, Domdi L, Soneya S, Reddy GS, Bethu MS, et al. Biogenesis of silver nanoparticles using leaf extract of Indigofera hirsuta L. and their potential biomedical applications (3-in-1 system). Artif Cells, Nanomed, Biotechnol. 2018;46(Supp 1):1138-48. doi: 10.1080/ 21691401.2018.1446967.

[236] Khatami M, Pourseyedi S, Khatami M, Hamidi H, Zaeifi M, Soltani L. Synthesis of silver nanoparticles using seed exudates of Sinapis arvensis as a novel bioresource, and evaluation of their antifungal activity. Bioresour Bioprocess. 2015;2(19):1-7. doi: 10.1186/s40643-015-0043-y.

[237] Sharma D, Sabela MI, Kanchi S, Mdluli PS, Singh G, Stenström TA, et al. Biosynthesis of $\mathrm{ZnO}$ nanoparticles using Jacaranda mimosifolia flowers extract: synergistic antibacterial activity and molecular simulated facet specific adsorption studies. J Photochem Photobiol, B. 2016;162:199-207. doi: 10.1016/j.jphotobiol.2016.06.043.

[238] Manikandan R, Beulaja M, Thiagarajan R, Palanisam S, Goutham G, Koodalingam A, et al. Biosynthesis of silver nanoparticles using aqueous extract of Phyllanthus acidus $L$. fruits and characterization of its anti-inflammatory effect against $\mathrm{H}_{2} \mathrm{O}_{2}$ exposed rat peritoneal macrophages. Process Biochem. 2017;55:172-81. doi: 10.1016/ j.procbio.2017.01.023.

[239] Kumar S, Bhattacharya W, Singh M, Halder D, Mitra A. Plant latex capped colloidal silver nanoparticles: a potent anti-biofilm and fungicidal formulation. J Mol Liq. 2017; 230(Suppl C):705-13. doi: 10.1016/j.molliq.2017.01.004.

[240] Kumar PN, Sakthivel K, Balasubramanian V. Microwave assisted biosynthesis of rice shaped $\mathrm{ZnO}$ nanoparticles using Amorphophallus konjac tuber extract and its application in dye sensitized solar cells. Mater Sci Pol. 2017;35(1):111-9. doi: 10.1515/msp-2017-0029.

[241] Mattos BD, Rojas OJ, Magalhães WL. Biogenic silica nanoparticles loaded with neem bark extract as green, slowrelease biocide. J Cleaner Prod. 2017;142:4206-13. doi: 10.1016/j.jclepro.2016.11.183. 
[242] Hegazy H, Shabaan LD, Rabie G, Raie DS. Biosynthesis of silver nanoparticles using cell free callus exudates of Medicago sativa L. Pak J Bot. 2015;47(5):1825-9.

[243] Poovathinthodiyil R, Jie F, Scott LW. Completely "Green" synthesis and stabilization of metal nanoparticles. J Am Chem Soc. 2003;125(46):13940-1. doi: 10.1021/ja029267j.

[244] Nikhil RJ, Tapan KS, Tarasankar P. Growing small silver particle as redox catalyst. J Phys Chem B. 1999;103:115-21. doi: 10.1021/jp982731f

[245] Tripathi GNR. P-benzosemiquinone radical anion on silver nanoparticles in water. J Am Chem Soc. 2003;125(5):1178-9. doi: 10.1021/ja029049q.

[246] Wei W, Sanford AA. Photochemical incorporation of silver quantum dots in monodisperse silica colloids for photonic crystal applications. J Am Chem Soc. 2001;123(50):12528-35. doi: 10.1021/ja011262j.

[247] Cui Y, Lieber CM. Functional nanoscale electronic devices assembled using silicon nanowire building blocks. Science. 2001;291(5505):851-3. doi: 10.1126/science.291.5505.851.

[248] Adam DM, Richard PVD. Single silver nanoparticles as realtime optical sensors with zeptomole sensitivity. Nano Lett. 2003;3(8):1057-62. doi: 10.1021/nl034372s.

[249] Erisin Ü, Oral O, Huseyin K, Esma Y, Bahattin Ç. Comparison of silver-coated dressing (Acticoat ${ }^{\mathrm{TM}}$ ), chlorhexidine acetate $0.5 \%$ (Bactigrass ${ }^{\circledR}$ ), and fusidic acid $2 \%$ (Fucidin ${ }^{\circledR}$ ) for topical antibacterial effect in methicillin-resistant staphylococci-contaminated, full skin thicknessrat burn wounds. Burns. 2005;31(7):874-7. doi: 10.1016/j.burns.2005.05.002.

[250] Babita B, Vivek P, Rajender SV. Glutathione promoted expeditious green synthesis of silver nanoparticles in water using microwaves. Green Chem. 2009;11:926-30. doi: 10.1039/b902184a.

[251] Qu V, Porter R, Shan F, Carter JD, Guo T. Synthesis of tubular gold and silver nanoshells using silica nanowire core templates. Langmuir. 2006;22(14):6367-74. doi: 10.1021/ la060359m.

[252] Feng G, Qingyi L, Sridhar K. Interface reaction for the selfassembly of silver nanocrystals under microwave-assisted solvothermal conditions. Chem Mater. 2005;17(4):856-60. doi: $10.1021 / \mathrm{cm} 048663 \mathrm{t}$

[253] Pierre YS, Ronaldo H-U, Kamar TE. Preparation of colloidal silver dispersions by the polyol process. J Mater Chem. 1997;7:293. doi: 10.1039/A605347E.

[254] Shankar SS, Rai A, Ahmad A, Shastry M. Rapid synthesis of $\mathrm{Au}, \mathrm{Ag}$, and bimetallic $\mathrm{Au}$ core-Ag shell nanoparticles using Neem (Azadirachta indica) leaf broth. J Colloid Interface Sci. 2004;275(2):496-502. doi: 10.1016/j.jcis.2004.03.003.

[255] Kundu S, Mandal M, Ghosh SK, Pal T. Photochemical deposition of SERS active silver nanoparticles on silica gel and their application as catalysts for the reduction of aromatic nitro compounds. J Colloid Interface Sci. 2004;272(1):134-44. doi: 10.1016/j.jcis.2003.11.046.

[256] Marignier JL, Belloni J, Delcourt MO, Chevalier JP. Microaggregates of non-noble metals and bimetallic alloys prepared by radiation-induced reduction. Nature. 1985;317:344-5. doi: 10.1038/317344a0.

[257] Bo H, Shang BW, Zhang M, Yu S-H. Microwave-assisted rapid facile "Green" synthesis of uniform silver nanoparticles: self-assembly into multilayered films and their optical properties. J Phys Chem C. 2008;112(30):11169-74. doi: 10.1021/jp801267j.

[258] Gerbec JA, Magana D, Washington A, Strouse GF. Microwaveenhanced reaction rates for nanoparticle synthesis. J Am Chem Soc. 2005;127(45):15791-800. doi: 10.1021/ ja052463g.

[259] Vivek P, Mallikarjuna NN, Rajander VS. The synthesis and applications of a micro-pine-structured nanocatalyst. Chem Commun. 2008;47:6318-20. doi: 10.1039/b814715a.

[260] Stone JW, Sisco PN, Goldsmith EC, Baxter SC, Murphy CJ. Using gold nanorods to probe cell-induced collagen deformation. Nano Lett. 2007;7(1):116-25. doi: 10.1021/nl062248d.

[261] Wiley B, Sun Y, Xia Y. Synthesis of silver nanostructures with controlled shapes and properties. Acc Chem Res. 2007;40(10):1067-76. doi: 10.1021/ar7000974.

[262] Benjamin W, Thurston H, Yugang S, Younan X. Polyol synthesis of silver nanoparticles: use of chloride and oxygen to promote the formation of single-crystal, truncated cubes and tetrahedrons. Nano Lett. 2004;4(10):2057. doi: 10.1021/ nl048559a.

[263] Catherine JM, Anand MG, Simona EH, Christopher JO. Onedimensional colloidal gold and silver nanostructures. Inorg Chem. 2006;45:7544. doi: 10.1021/ic0519382.

[264] Wiley BJ, Chen Y, McLellan JM, Xiong Y, Li ZY, Ginger D, et al. Synthesis and optical properties of silver nanobars and nanorice. Nano Lett. 2007;4:1032-8. doi: 10.1021/ nl070214f.

[265] Yujie X, Honggang C, Benjamin JW, Jinguo W, Moon JK, Younan X. J Am Chem Soc. 2007;129(12):3665-75. doi: 10.1021/ja0688023.

[266] Jixiang F, Hongjun Y, Peng K, Yan Y, Xiaoping S, Bingjun D. Dendritic silver nanostructure growth and evolution in replacement reaction. Cryst Growth Des. 2007;7(5):864-7. doi: $10.1021 / \operatorname{cg} 0604879$.

[267] Arun N, Lars L, Mats B. Laser-assisted synthesis of ultra small metal nanoparticles. Appl Surf Sci. 2003;208:137-41. doi: 10.1016/S0169-4332(02)01352-1.

[268] Song H, Rioux RM, Hoefelmeyer JD, Komor R, Niesz K, Grass $M$, et al. Hydrothermal growth of mesoporous SBA-15 silica in the presence of PVP-stabilized Pt nanoparticles: synthesis, characterization, and catalytic properties. J Am Chem Soc. 2006;128(9):3027-37. doi: 10.1021/ ja057383r.

[269] Cheng CW, Dong HC, Ting CH. Synthesis of palladium nanoparticles in water-in-oil microemulsions. Colloids Surf A. 2001;189:145-54. doi: 10.1016/S0927-7757(01)00576-3.

[270] Raveendran P, Fu J, Wallen SL. Completely "green" synthesis and stabilization of metal nanoparticles. J Am Chem Soc. 2003;125:13940-1. doi: 10.1021/ja029267j.

[271] Mallikarjuna NN, Rajender SV. Green approach to bulk and template-free synthesis of thermally stable reduced polyaniline nanofibers for capacitor applications. Green Chem. 2007;9:632-7. doi: 10.1039/B614633C

[272] Naik RR, Stringer SJ, Agarwal G, Jones SE, Stone MO. Biomimetic synthesis and patterning of silver nanoparticles. Nat Mater. 2002;1(3):169-72. doi: 10.1038/nmat758.

[273] Kumar A, Vemula PK, Ajayan PM, John G. Silver-nanoparticleembedded antimicrobial paints based on vegetable oil. Nat Mater. 2008;7(3):236-41. doi: 10.1038/nmat2099. 
[274] El-Sayed MA. Some interesting properties of metals confined in time and nanometer space of different shapes. Acc Chem Res. 2001;34(4):257-64. doi: 10.1021/ar960016n.

[275] Fang X-S, Ye C-H, Zhang L-D, Wang Y-H, Wu Y-C. Temperature-controlled catalytic growth of $\mathrm{ZnS}$ nanostructures by the evaporation of ZnS nanopowders. Adv Funct Mater. 2005;15:63. doi: 10.1002/adfm.200305008.

[276] Xia Y, Yang P, Sun Y, Wu Y, Mayers B, Gates B, et al. One dimensional nanostructures; synthesis, characterization, and applications. Adv Mater. 2003;15(5):353-89. doi: 10.1002/adma.200390087.

[277] Burda C, Chen X, Narayanan R, El-Sayed MA. Chemistry and properties of nanocrystals of different shapes. Chem Rev. 2005;105(4):1025-102. doi: 10.1021/cr030063a.

[278] Fang XS, Ye CH, Peng XS, Wang YH, Wu YC, Zhang LD. Temperature-controlled growth of $\alpha-\mathrm{Al}_{2} \mathrm{O}_{3}$ nanobelts and nanosheets. J Mater Chem. 2003;13:3040-3. doi: 10.1039/ B309193G.

[279] Petroski JM, Wang ZL, Green TC, El-Sayed MA. Kinetically controlled growth and shape formation mechanism of platinum nanoparticles. J Phys Chem B. 1998;102(18):3316-20. doi: 10.1021/jp981030f.

[280] Zheng L, Li J. Reactivity of anatase $\mathrm{TiO}_{2}$ nanoparticles: the role of the minority (001) surface. J Phys Chem B. 2005;109(42):19560-2. doi: 10.1021/jp055311g.

[281] Park SH, Barish R, Li H, Reif JH, Finkelstein G, Yan H, et al. Three-helix bundle DNA tiles self-assemble into 2D lattice or 1D templates for silver nanowires. Nano Lett. 2005;5(4):693-6. doi: 10.1021/nl050108i.

[282] Maye MM, Lim I-IS, Luo J, Rab Z, Rabinovich D, Liu T, et al. Mediator-template assembly of nanoparticles. J Am Chem Soc. 2005;127(5):1519-29. doi: 10.1021/ja044408y.

[283] In I, Jun YW, Kim YJ, Kim SY. Spontaneous one dimensional arrangement of spherical Au nanoparticles with liquid crystal ligands. Chem Commun. 2005;800-1. doi: 10.1039/ B413510E.

[284] Gao F, Lu Q, Komarneni S. Interface reaction for the selfassembly of silver nanocrystals under microwave-assisted solvothermal conditions. Chem Mater. 2005;17(4):856-60. doi: $10.1021 / \mathrm{cm} 048663 \mathrm{t}$.

[285] Jana NR. Shape effect in nanoparticle self-assembly. Angew Chem, Int Ed. 2004;43(12):1536-40. doi: 10.1002/ anie. 200352260.

[286] Nikoobakht B, Wang ZL, El-Sayed MA. Self-assembly of gold nanorods. J Phys Chem B. 2000;104(36):8635-40. doi: 10.1021/jp001287p.

[287] Pan ZW, Dai ZR, Wang ZL. Nanobelts of semiconducting oxides. Science. 2001;291(5510):1947-9. doi: 10.1126/ science.1058120.

[288] Hu J, Odom TW, Lieber CM. Chemistry and physics in one dimension: synthesis and properties of nanowires and nanotubes. Acc Chem Res. 1999;32(5):435-45. doi: 10.1021/ $\operatorname{ar} 9700365$.

[289] Caswell KK, Wilson JN, Bunz UH, Murphy CJ. Preferential endto-end assembly of gold nanorods by biotin-streptavidin connectors. J Am Chem Soc. 2003;125(46):13914-5. doi: 10.1021/ja037969i.

[290] Ankamwar B, Damle C, Ahmad A, Sastry M. Biosynthesis of gold and silver nanoparticles using Emblica Officinalis fruit extract, their phase transfer and transmetallation in an organic solution. J Nanosci Nanotechnol. 2005;5(10):1665-71. doi: 10.1166/jnn.2005.184.

[291] Priya VJ, Vijaykumar SI, Ashwini KS. Voltammetric behavior of certain vitamins and their determination in surfactant media. Anal Sci. 2001;17:i741-4. doi: 10.14891/ analscisp.17icas.0.i741.0.

[292] Guo S, DiPietro LA. Factors affecting wound healing. I Dent Res. 2010;89:219-29. doi: 10.1177/0022034509359125.

[293] Gershenfeld L. Povidone-iodine (PVP-I) as a vaginal microbicide. Am J Pharm Sci Support Public Health. 1962;134:278-91. PMID:13960582.

[294] Lavelle KJ, Doedens DJ, Kleit SA, Forney RB. lodine absorption in burn patients treated topically with povidoneiodine. Clin Pharmacol Ther. 1975;17:355-62. doi: 10.1002/ cpt1975173355.

[295] Hwang KY, Mun BC, Choi JS, Kim KH, Ahn JC. Two cases of allergic contact dermatitis to betadine $\AA$. Yeungnam Univ J Med. 1986;3(1):387-93. doi: 10.12701/yujm.1986.3.1.387.

[296] Leung AM, Braverman LE. Consequences of excess iodine. Nat Rev Endocrinol. 2014;10(3):136-42. doi: 10.1038/ nrendo.2013.251.

[297] Ghosh CK, Roy K. Chapter 8-Environmental and biological applications of nanoparticles. In: Nanotechnology: synthesis to applications. CRC Press; 2017. pp. 169-92. ISBN: 978-1138-03273-6.

[298] Ghosh T, Das AB, Jena B, Pradhan C. Antimicrobial effect of silver zinc oxide (Ag-ZnO) nanocomposite particles. Front Life Sci. 2015;8:47-54. doi: 10.1080/21553769.2014. 952048.

[299] Hebbalalu D, Lalley J, Nadagouda MN, Varma RS. Greener techniques for the synthesis of silver nanoparticles using plant extracts, enzymes, bacteria, biodegradable polymers, and microwaves. ACS Sustain Chem Eng. 2013;1(7):703-12. doi: $10.1021 /$ sc4000362.

[300] Khan ZUH, Khan A, Chen Y, Shah NS, Muhammad N, Khan AU, et al. Biomedical applications of green synthesized Nobel metal nanoparticles. J Photochem Photobiol B: Biol. 2017;173:150-64. doi: 10.1016/j.jphotobiol.2017.05.034.

[301] Khan AU, Yuan Q, Khan ZUH, Ahmad A, Khan FU, Tahir K, et al. An eco-benign synthesis of AgNPs using aqueous extract of Longan fruit peel: antiproliferative response against human breast cancer cell line MCF-7, antioxidant and photocatalytic deprivation of methylene blue. J Photochem Photobiol B: Biol. 2018;183:367-73. doi: 10.1016/ j.jphotobiol.2018.05.007.

[302] Khatami M, Alijani H, Sharifi I. Biosynthesis of bimetallic and core shell nanoparticles: their biomedical applications: a review. IET Nanobiotechnol Inst Eng Technol. 2018;12(7):879-87. doi: 10.1049/iet-nbt.2017.0308.

[303] Mohammadine Jad R, Karimi S, Iravani S, Varma RS. Plantderived nanostructures: types and applications. Green Chem. 2016;18:20-52. doi: 10.1039/C5GC01403D.

[304] Nasretdinova GR, Fazleeva RR, Mukhitova RK, Nizameev IR, Kadirov MK, Ziganshina AY, et al. Electrochemical synthesis of silver nanoparticles in solution. Electrochem Commun. 2015;50:69-72. doi: 10.1016/j.elecom.2014.11.016.

[305] Rajakumar G, Rahuman AA, Priyamvada B, Khanna VG, Kumar DK, Sujin PJ. Eclipta prostrata leaf aqueous extract mediated synthesis of titanium dioxide nanoparticles. Master Lett. 2012;68:115-7. doi: 10.1016/j.matlet.2011.10.038. 
[306] Shakeel M, Arif M, Yasin G, Li B, Khan AU, Khan FU, et al. Hollow mesoporous architecture: a high performance Bi-functional photoelectrocatalyst for overall water splitting. Electrochim Acta. 2018;268:163-72. doi: 10.1016/ j.electacta.2018.02.024.

[307] Singh H, Du J, Yi T-H. Biosynthesis of silver nanoparticles using Aeromonas sp. THG-FG1.2 and its antibacterial activity against pathogenic microbes. Artif Cells, Nanomed Biotechnol. 2017;45(3):584-90. doi: 10.3109/ 21691401.2016.1163715.

[308] Gopinath K, Karthika V, Sundaravadivelan C, Gowri S, Arumugam A. Mycogenesis of cerium oxide nanoparticles using Aspergillus niger culture filtrate and their applications for antibacterial and larvicidal activities. J Nanostruct Chem. 2015;5:295-303. doi: 10.1007/s40097-015-0161-2.

[309] Kitching M, Ramani M, Marsili E. Fungal biosynthesis of gold nanoparticles: mechanism and scale up. Microb Biotechnol. 2015;8:904-17. doi: 10.1111/1751-7915.

[310] Mortazavi SM, Khatami M, Sharifi I, Heli H, Kaykavousi K, Sobhani Poor MH, et al. Bacterial biosynthesis of gold nanoparticles using Salmonella enterica subsp. enterica serovar Typhi isolated from blood and stool specimens of patients. J Clust Sci. 2017;28:2997-3007. doi: 10.1007/ s10876-017-1267-0.

[311] Mortazavi SM, Khatami M, Sharifi I, Heli H, Kaykavousi K, Sobhani Poor MH, et al. Bacterial biosynthesis of gold nanoparticles using Salmonella enterica subsp. enterica serovar Typhi isolated from blood and stool specimens of patients. J Clust Sci. 2017;28:2997-3007. doi: 10.1007/ s10876-017-1267-0.

[312] Ponmurugan P. Biosynthesis of silver and gold nanoparticles using Trichoderma atroviride for the biological control of Phomopsis canker disease in tea plants. IET Nanobiotechnol. 2017;11(3):261-7. doi: 10.1049/iet-nbt.2016.0029.

[313] Nadagouda MN, Iyanna N, Lalley J, Han C, Dionysiou DD, Varma RS. Synthesis of silver and gold nanoparticles using antioxidants from blackberry, blueberry, pomegranate, and turmeric extracts. ACS Sustain Chem Eng. 2014;2:1717-23. doi: $10.1021 /$ sc500237k.

[314] Barui AK, Kotcherlakota R, Patra CR. Biomedical applications of zinc oxide nanoparticles. Inorganic Frameworks as Smart Nanomedicines. Elsevier; 2018. pp. 239-78. doi: 10.1016/ B978-0-12-813661-4.00006-7.

[315] Charbgoo F, Ramezani M, Darroudi M. Bio-sensing applications of cerium oxide nanoparticles: advantages and disadvantages. Biosens Bioelectron. 2017;96:33-43. doi: 10.1016/j.bios.2017.04.037.

[316] Hameed ASH, Karthikeyan C, Ahamed AP, Thajuddin N, Alharbi NS, Alharbi SA, et al. In vitro antibacterial activity of $\mathrm{ZnO}$ and $\mathrm{Nd}$ doped $\mathrm{ZnO}$ nanoparticles against ESBL producing Escherichia coli and Klebsiella pneumoniae. Sci Rep. 2016;6(24312):1-11. doi: 10.1038/srep24312.

[317] Karthik K, Dhanuskodi S, Gobinath C, Prabukumar S, Sivaramakrishnan S. Multifunctional properties of microwave assisted $\mathrm{CdO}-\mathrm{NiO}-\mathrm{ZnO}$ mixed metal oxide nanocomposite: enhanced photocatalytic and antibacterial activities. J Mater Sci: Mater Electron. 2018;29:5459-71. doi: 10.1007/ s10854-017-8513-y.

[318] Karthik K, Dhanuskodi S, Gobinath C, Prabukumar S, Sivaramakrishnan S. Nanostructured $\mathrm{CdO}-\mathrm{NiO}$ composite for multifunctional applications. J Phys Chem Solids. 2018;112:106-18. doi: 10.1016/j.jpcs.2017.09.016.

[319] Mirzaei H, Darroudi M. Zinc oxide nanoparticles: biological synthesis and biomedical applications. Ceram Int. 2017;43:907-14. doi: 10.1016/j.ceramint.2016.10.051.

[320] Singh H, Du J, Singh P, Yi T, H. Extracellular synthesis of silver nanoparticles by Pseudomonas sp. THG-LS1.4 and their antimicrobial application. J Pharm Anal. 2018;8(4):258-64. doi: 10.1016/j.jpha.2018.04.004.

[321] Singh H, Du J, Yi T-H. Biosynthesis of silver nanoparticles using Aeromonas sp. THG-FG1.2 and its antibacterial activity against pathogenic microbes. Artif Cells, Nanomed Biotechnol. 2017:45:584-90. doi: 10.3109/21691401.2016.1163715.

[322] Politano AD, Campbell KT, Rosenberger LH, Sawyer RG. Use of silver in the prevention and treatment of infections: silver review. Surg Infect. 2013;14(1):8-20. doi: 10.1089/sur.2011.097.

[323] Agu RC, Palmer GH. The effect of temperature on the modification of sorghum and barley during malting. Process Biochem. 1997;32:501-7. doi: 10.1016/S0032-9592(97)00002-2.

[324] Novellie L. Kaffircorn malting and brewing studies XI. Effect of malting conditions on the diastatic power of kaffircorn malts. J Sci Food Agric. 1962;13:115-20. doi: 10.1002/ jsfa.2740130210.

[325] Asiedu JJ. La transformation des produits agricoles en zone tropicale: approche technologique. Paris: Karthala; 1991.

[326] Lyumugabe L, Kamaliza G, Bajyana E, Thonart PH. Microbiological and physico-chemical characteristics of Rwandese traditional beer "Ikigage". Afr J Biotechnol. 2010;9(27):4241-6, ISSN: 1684-5315.

[327] Kayodé APP, Adegbidi A, Hounhouigan DJ, Linnemann AR. Quality of farmer's varieties of sorghum and derived foods as perceived by consumers in Benin. Ecol Food Nutr. 2005;44:271-94. doi: 10.1080/03670240500187302.

[328] Dicko MH, Gruppen H, Traoré AS, Voragen AGJ, Van Berkel WJH. Sorghum grain as human food in Africa: relevance of content of starch and amylase activities. Afr J Biotechnol. 2006;5(5):384-95, ISSN 1684-5315.

[329] Ekundayo JA. The production of pito, a Nigerian fermented beverage. J Food Technol. 1969;4:217-25. doi: 10.1111/ j.1365-2621.1969.tb01517.x.

[330] Faparusi SI, Olofinboba MO, Ekwundayo JA. The microbiology of burukutu beer. Z Allg Mikrobiol. 1973;13:563-8. doi: 10.1002/jobm.19730130705.

[331] Chevassus-Agnes S, Favier JC, Joseph A. Traditional technology and nutritive value of Cameroon sorghum beers. Cah Onarest. 1979;2:83-112.

[332] Lyumugabe F, Gros J, Nzungize J, Bajyana E, Thonart P. Characteristics of African traditional beers brewed with sorghum malt: a review. Biotechnol Agron Soc Env. 2012;16(4):509-30, ISSN:1370-6233.

[333] Chamunorwa AT, Feresu SB, Mutukumira AN. Identification of lactic acid bacteria isolated from opaque beer (Chibuku) for potential use as a starter culture. J Food Technol Afr. 2002;7:93-97. doi: 10.4314/jfta.v7i3.19239.

[334] Dirar HA. A microbiological study of Sudanese merissa brewing. J Food Sci. 1978;43:163-8. doi: 10.1111/j.13652621.1978.tb07388.x.

[335] Tisekwa B. Improvement of traditional manufacturing of sorghum beer (mtama) in Tanzania. PhD thesis. Belgium: Ghent University; 1989. 
[336] Maoura N, Mbaiguinam M, Nguyen HV, Gaillardin C, Pourquie J. Identification and typing of the yeast strains isolated from bili bili, a traditional sorghum beer of Chad. Afr J Biotechnol. 2005;4:646-56. doi: 10.5897/AJB2005.000-3117.

[337] Haggblade S, Holzapfel H. Industrialization of Africa's indigenous beer brewing. In: Streinrous KH, editor. Industrialization of indigenous fermented foods. 2nd ed. New York, USA: CRC Press; 2004.

[338] Rooney LW, Serna-Saldivar SO. Sorghum. In: Lorenz KJ, Kulp K, editor. Handbook of cereal science and technology. New York, USA: Marcel Dekker Inc.; 1991. pp. 233-70. ISBN: 9780824782948.

[339] Glennie CW, Wight AW. Dextrins in sorghum beer. J Inst Brew. 1986;92:384-6. doi: 10.1002/j.2050-0416.1986.tb04428.x.

[340] Aisien AO. Enzyme modification of sorghum endosperm during seedling growth and malting. J Sci Food Agric. 1982;33:754-9. doi: 10.1002/jsfa.2740330811.

[341] Palmer GH. Enzymic degradation of the endosperm cell walls of germinated sorghum. World J Microbiol Biotechnol. 1991;7(1):17-21. doi: 10.1007/BF02310913.

[342] Bajomo MF, Young TW. Fermentation of wort from $100 \%$ of raw sorghum and enzyme. J Inst Brew. 1994;100:79-84. doi: 10.1002/j.2050-0416.1994.tb00810.x.

[343] Kayodé APP, Hounhouigana JD, Nout MJR. Impact of brewing process operations on phyta, phenolic compounds and in vitro solubility of iron and zinc in opaque sorghum beer. LWT. 2007;40(5):834-41. doi: 10.1016/ j.lwt.2006.04.001.

[344] Kayodé APP, Hounhouigana JD, Nout MJR, Niehof A. Household production of sorghum beer in Benin: technological and socio-economic aspects. Int J Consum Stud. 2007;31(3):258-64. doi: 10.1111/j.1470-6431.2006. 00546.x.

[345] Sefa-Dedeh S, Sanni Al, Tetteh G, Sakyi-Dawson E. Yeasts in the traditional brewing of pito in Ghana. World J Microbiol Biotechnol. 1999;15(5):593-7. doi: 10.1023/ A:1008955300156.

[346] Sanni Al, Onilude AA, Fadahusi IF, Afolabi RO. Microbial deterioration of traditional alcoholic beverages in Nigeria. Food Res Int. 1999;32:163-7. doi: 10.1016/S0963-9969(99) 00068-X.

[347] Xuchuan J, Aibing Y. One-step approach for the synthesis and self-assembly of silver nanoparticles. J Nanosci Nanotechnol. 2010;10(11):7643-7. doi: 10.1166/ jnn.2010.2763.

[348] Sudhasree S, Shakila Banu A, Brindha P, Kurian GA. Synthesis of nickel nanoparticles by chemical and green route and their comparison in respect to biological effect and toxicity. Toxicol Env Chem. 2014;96(5):743-54. doi: $10.1080 / 02772248.2014 .923148$. 